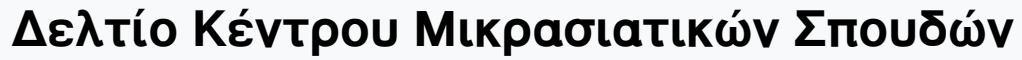

Tóp. 11 (1995)

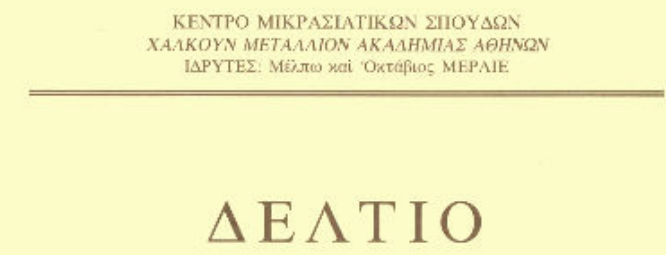

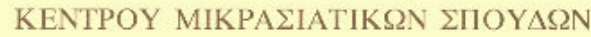

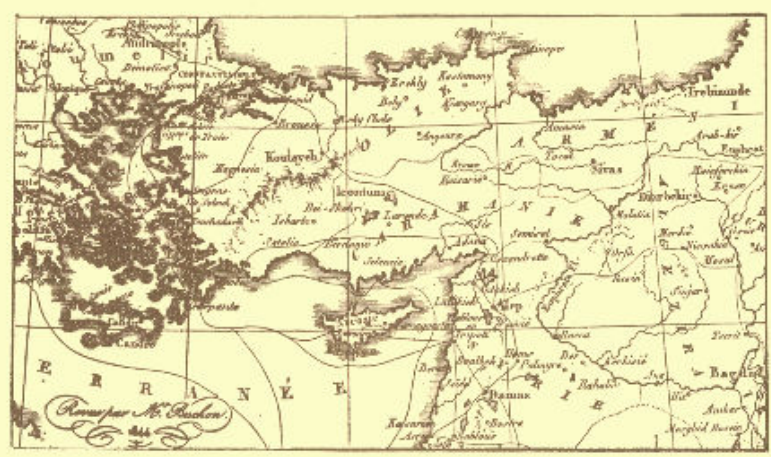

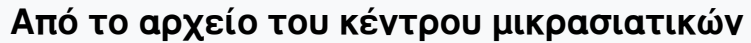 бாоบठ์́v}

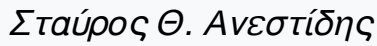

doi: $10.12681 /$ deltiokms.59

\section{TOMOZ ENAEKATOE}

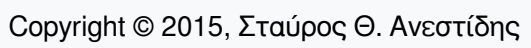

\section{(c) (7)(2)}

Aঠ¿ıı Xpńбnৎ Creative Commons Attribution-NonCommercial-ShareAlike 4.0.

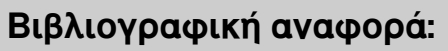

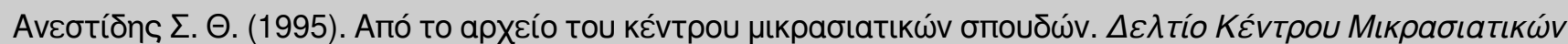

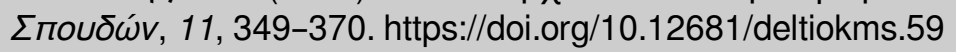




$\Sigma T A Y P O \Sigma \Theta$. ANE $\Sigma T I \Delta H \Sigma$

\section{AПО TO APXEIO TOY KENTPOY MIKPA $\Sigma I A T I K \Omega N ~ \Sigma \Pi O Y \triangle \Omega N$}

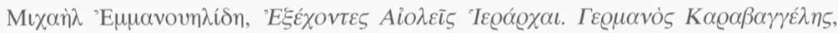
['AOńvo, 1962].

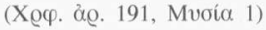

\section{I. $\operatorname{EI} \Sigma A \Gamma \Omega \Gamma H$}

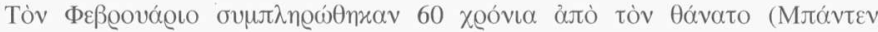

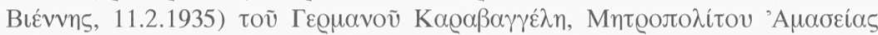

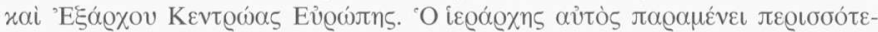

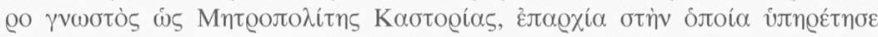

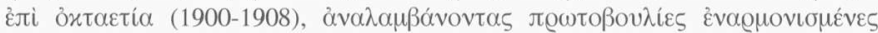

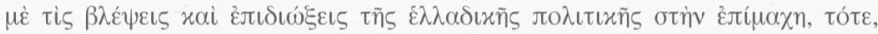

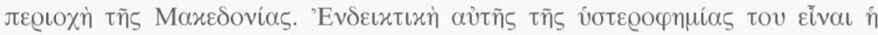

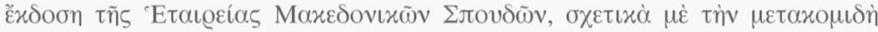

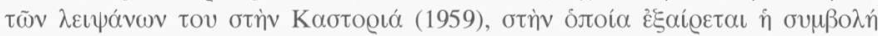

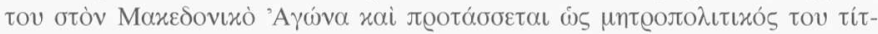

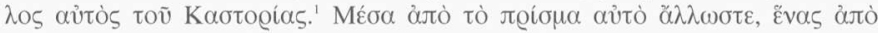

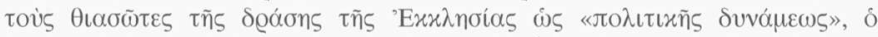

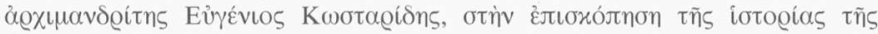

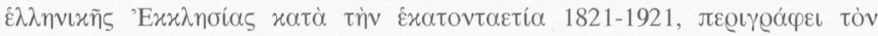

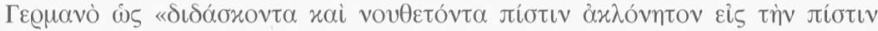

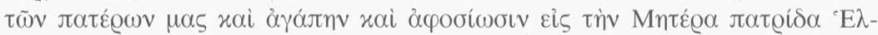

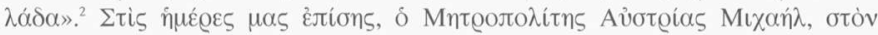

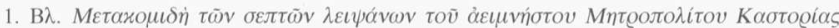

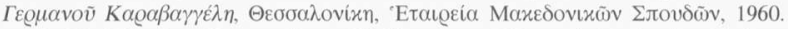

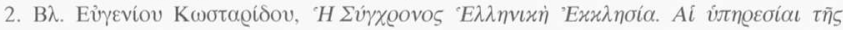
'Exx

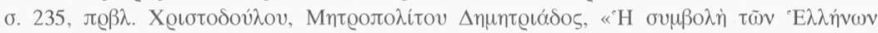




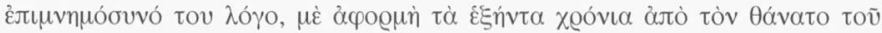

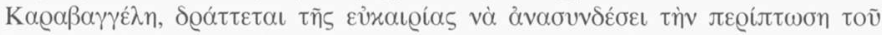

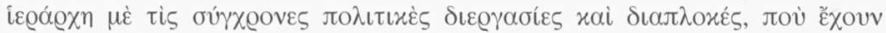

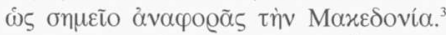

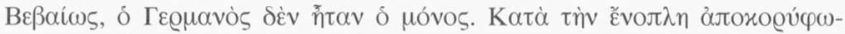

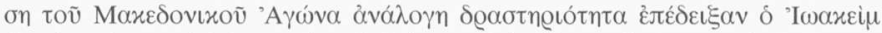

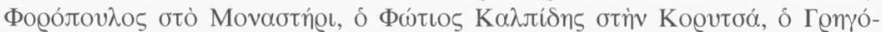

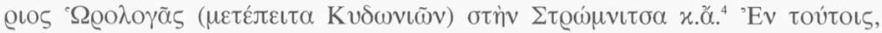

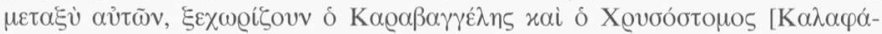

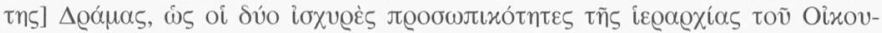

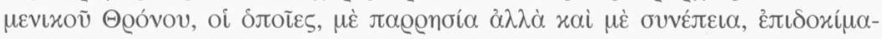

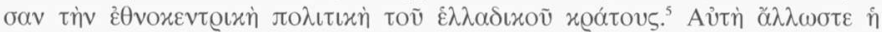

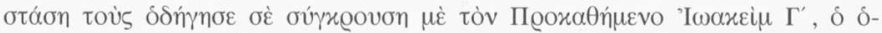

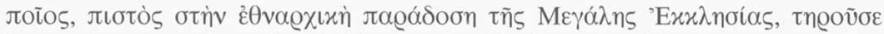

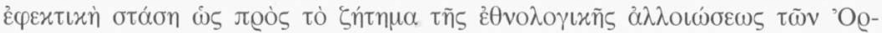

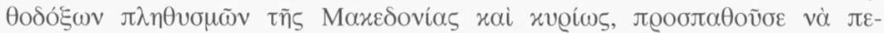

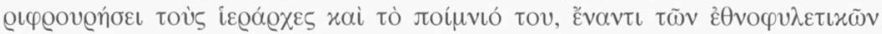

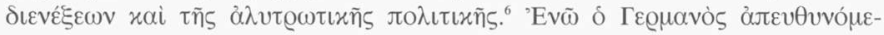

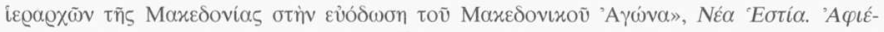

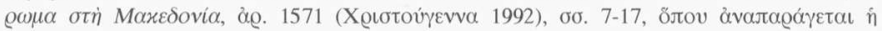

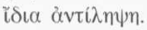

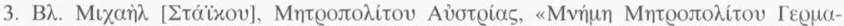

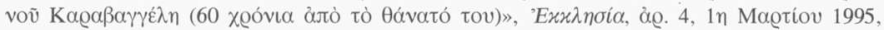
б. 158 .

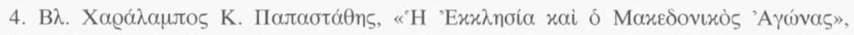

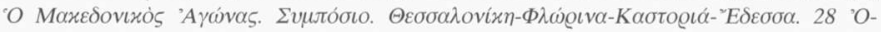

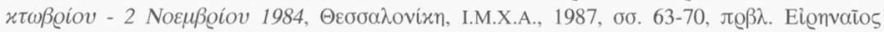

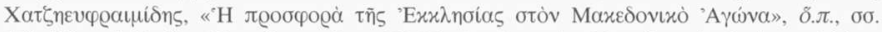

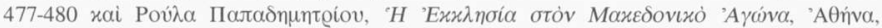
1991, бо. 29-65.

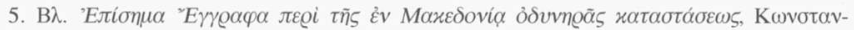

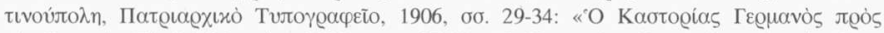

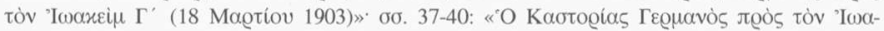

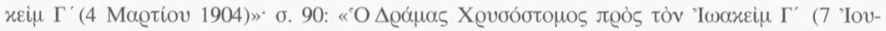

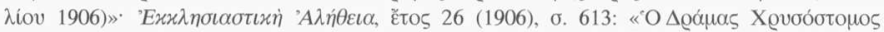

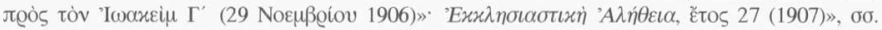

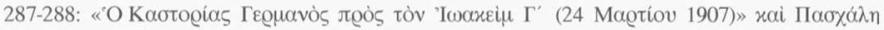

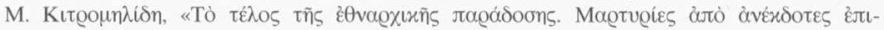

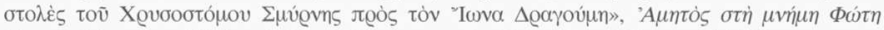

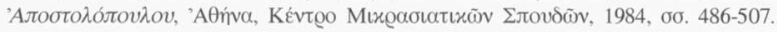

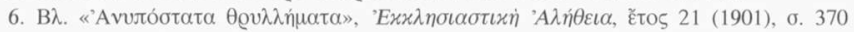

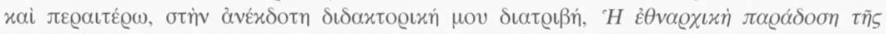

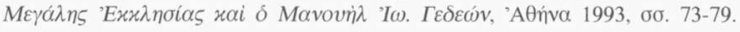




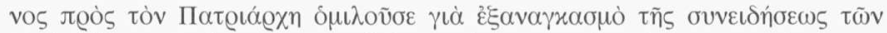

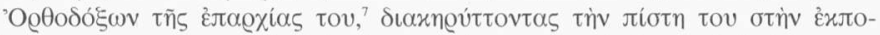

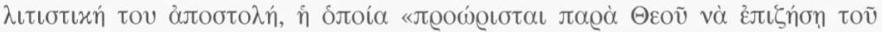

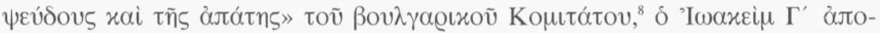

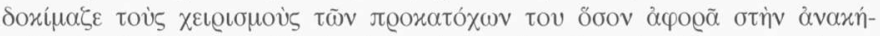

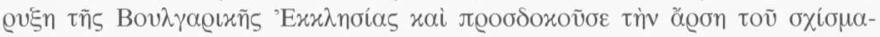

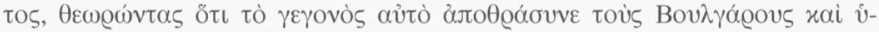

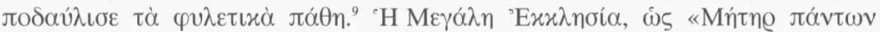

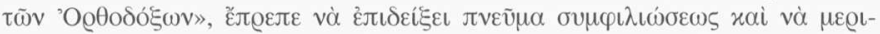

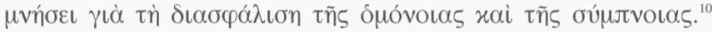

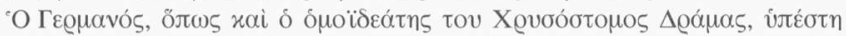

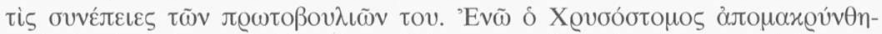

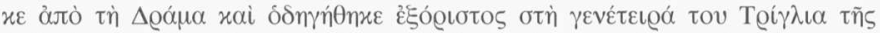

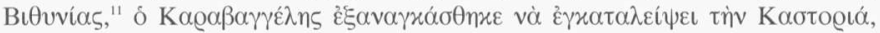

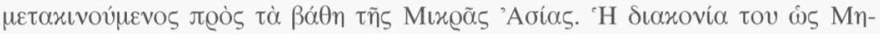

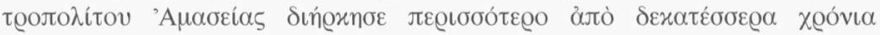

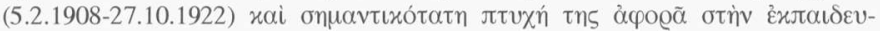

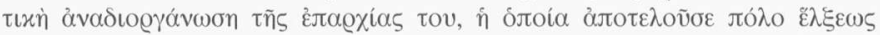

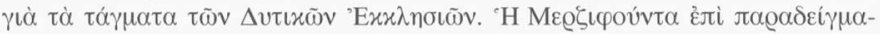

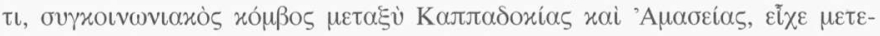

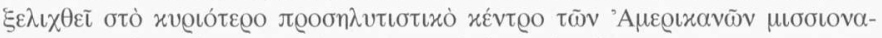

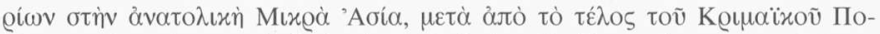

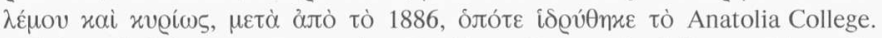

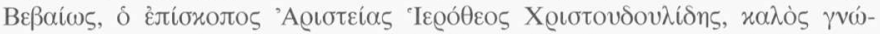

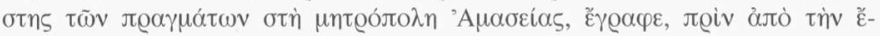

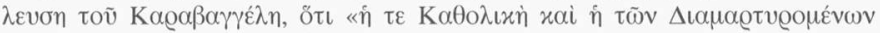

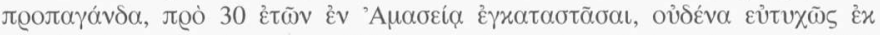

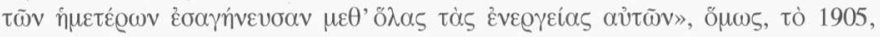

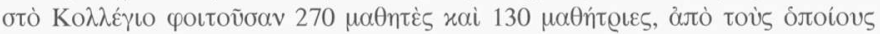

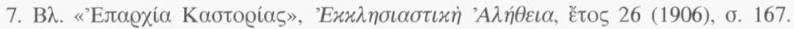

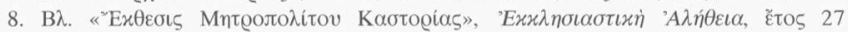
(1907), б. 287.

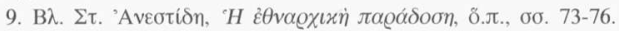

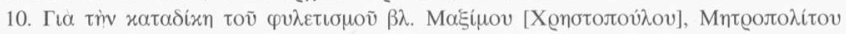

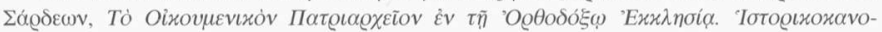

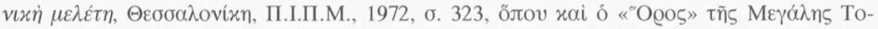

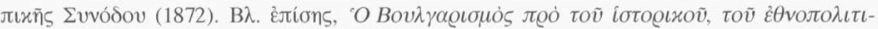

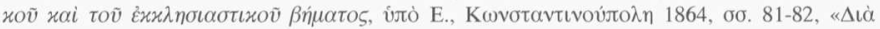

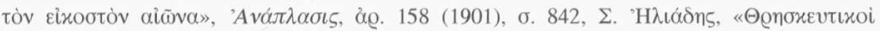

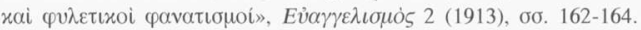

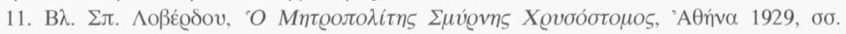
$117-120$. 


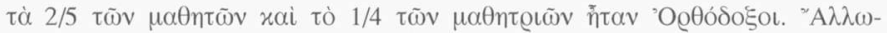

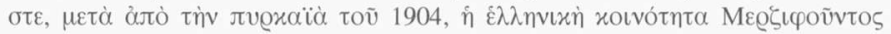

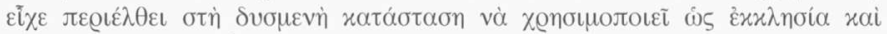

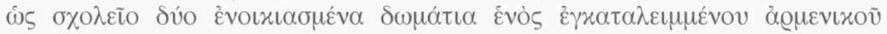

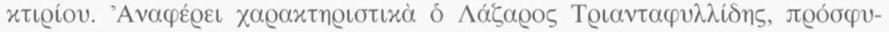

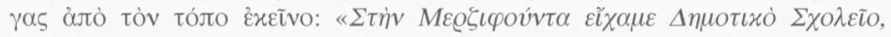

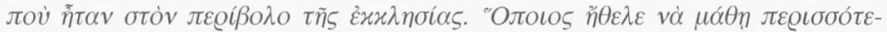

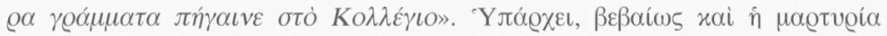

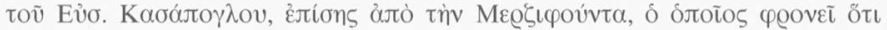

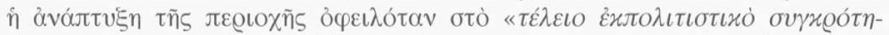

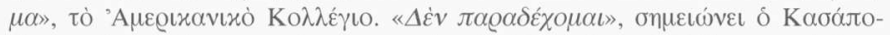

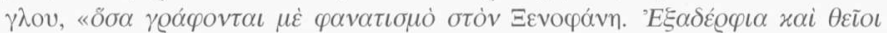

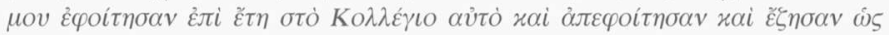

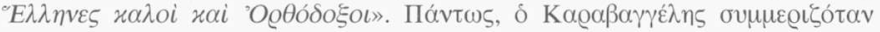

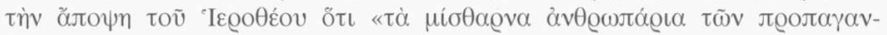

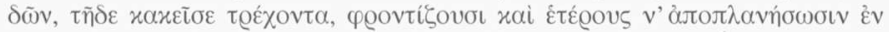

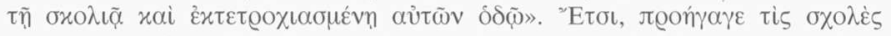

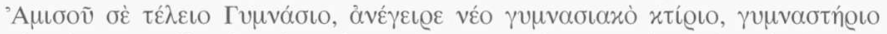

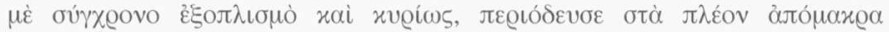

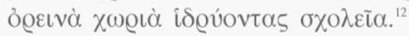

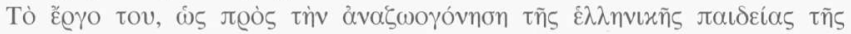

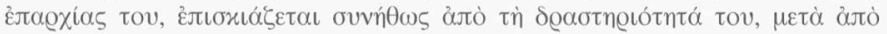

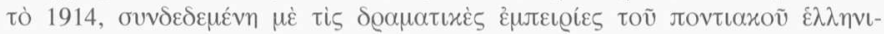

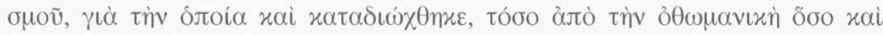

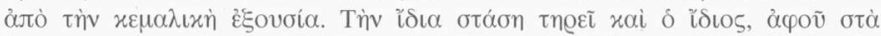

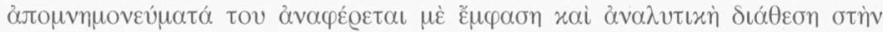

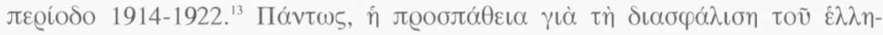

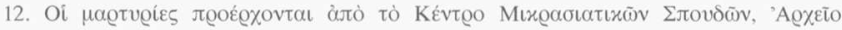

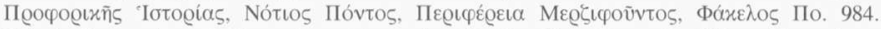

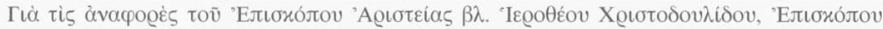

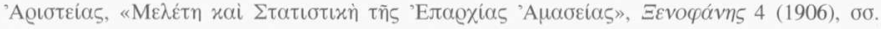

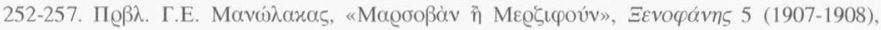

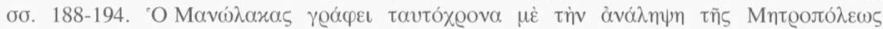

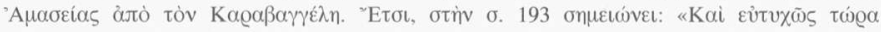

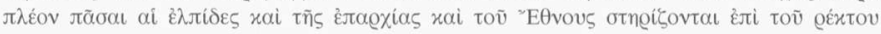

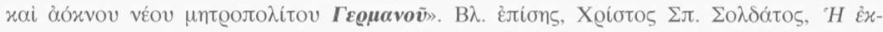

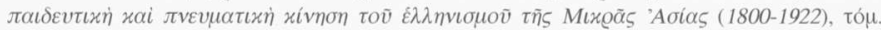

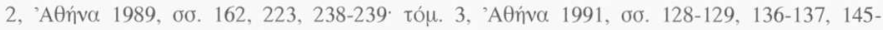

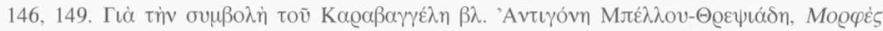

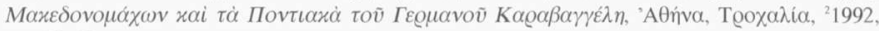
бб. 92-95.

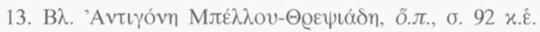




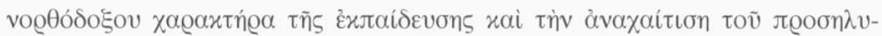

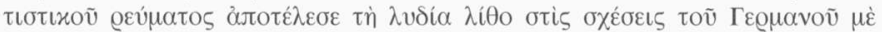

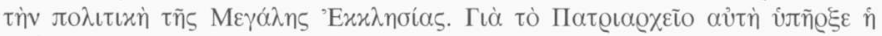

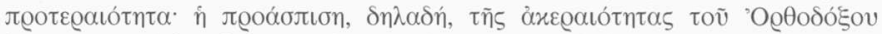

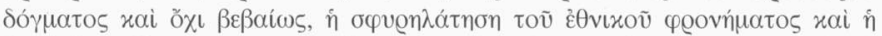

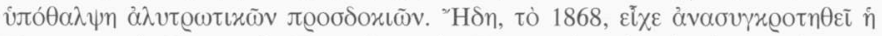

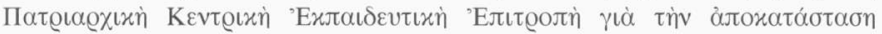

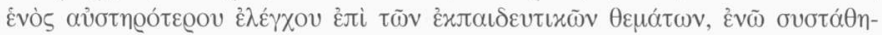

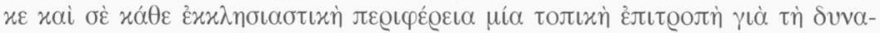

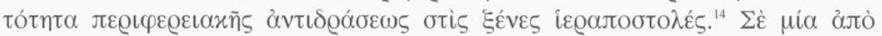

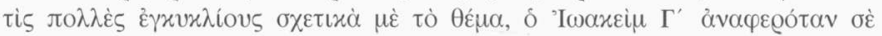

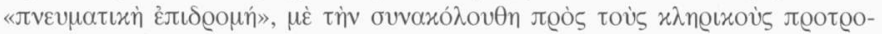

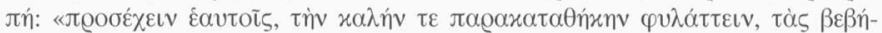

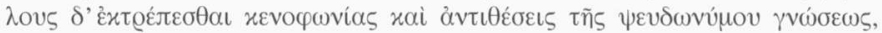

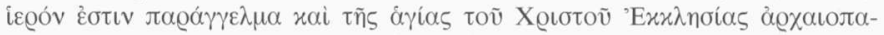

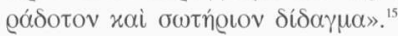

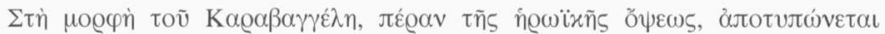

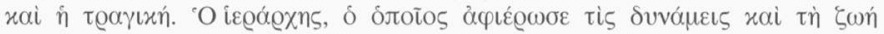

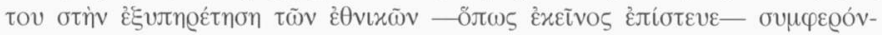

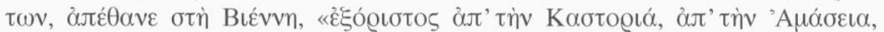

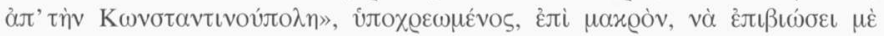

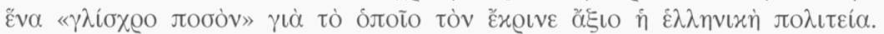

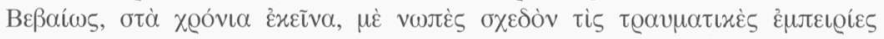

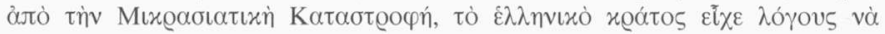

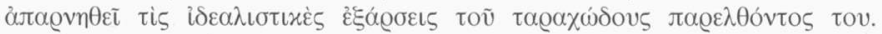

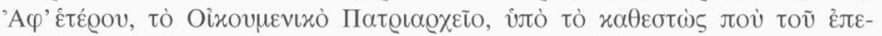

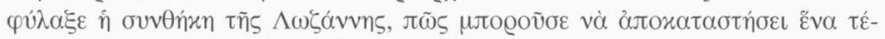

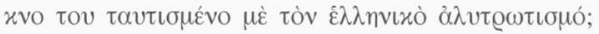

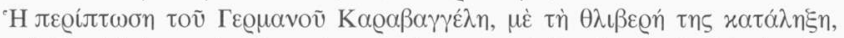

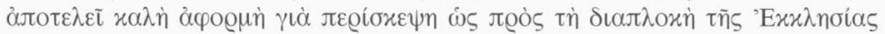

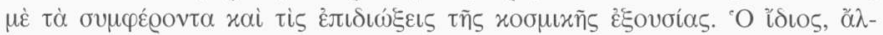

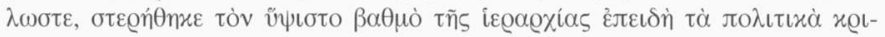

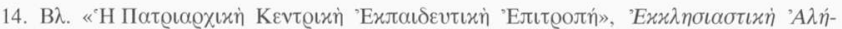

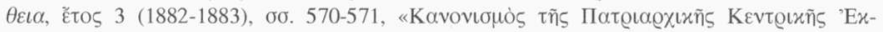

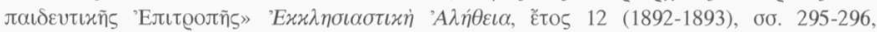

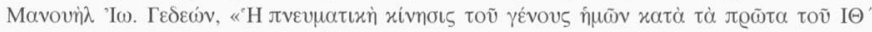

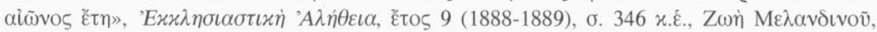

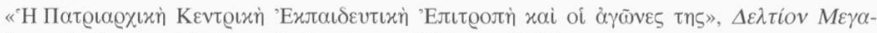

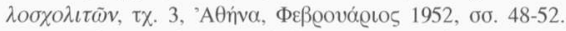

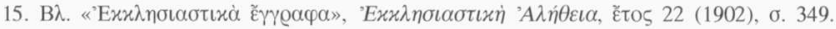




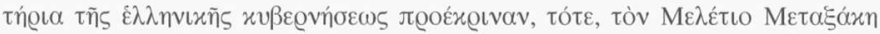

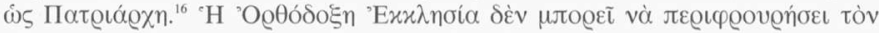

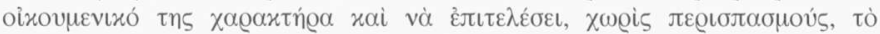

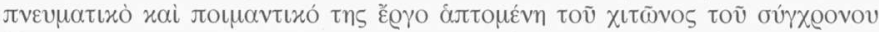

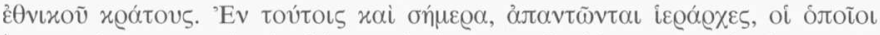

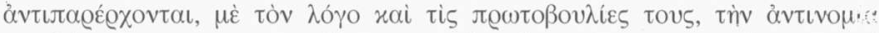

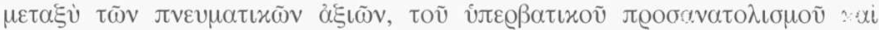

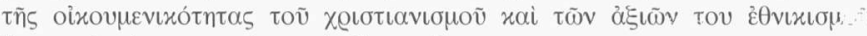

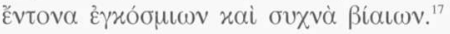

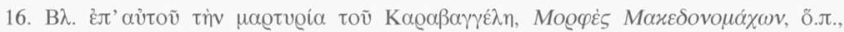
бо. 131-135.

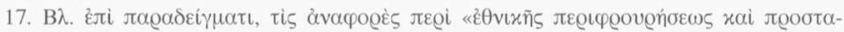

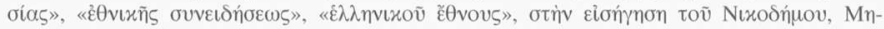

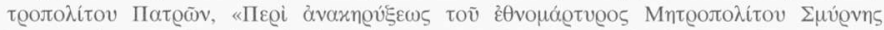

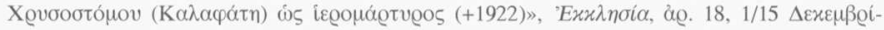

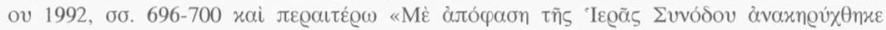

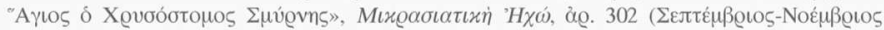

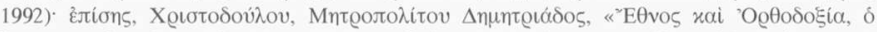

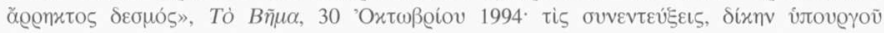

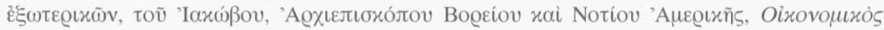

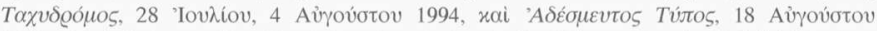

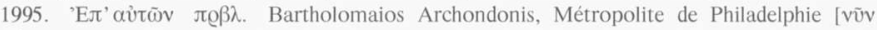

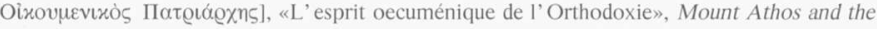

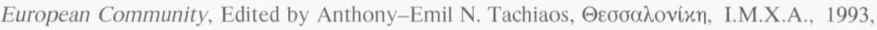

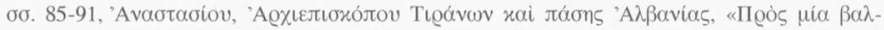

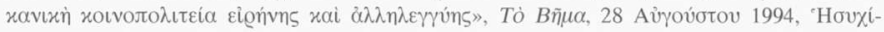

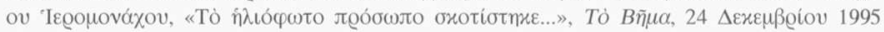

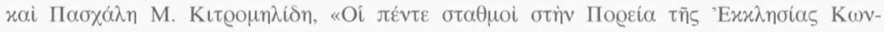

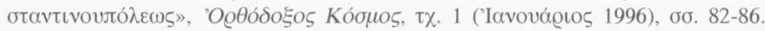




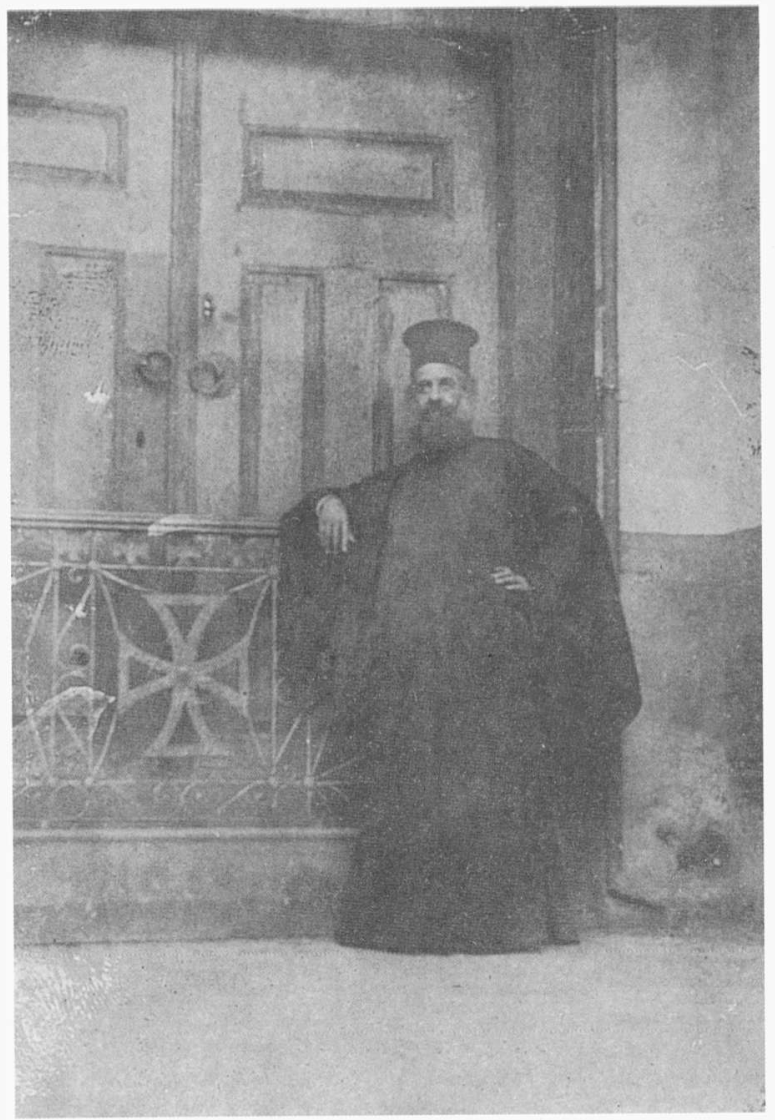

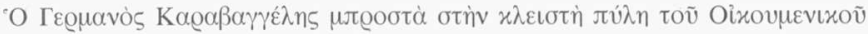

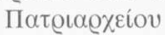

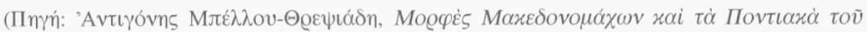

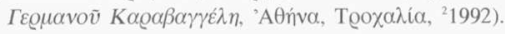




\section{TO KEIMENO}

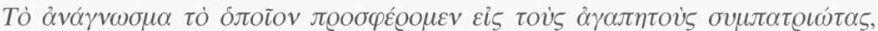

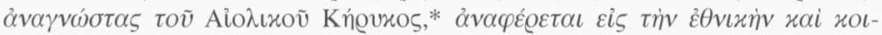

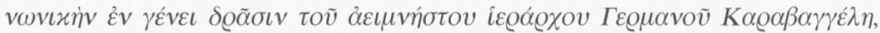

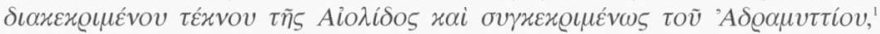

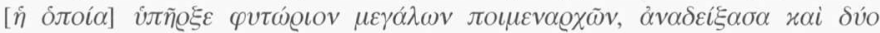

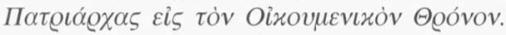

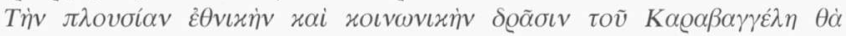

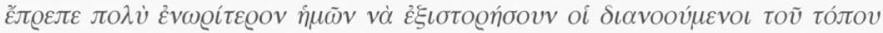

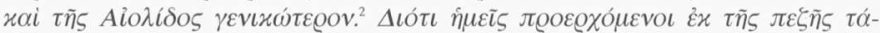

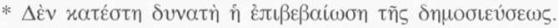

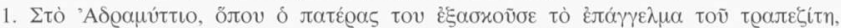

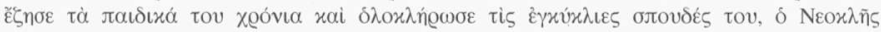

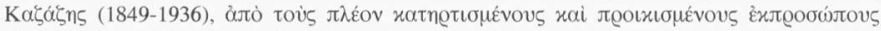

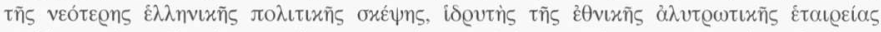

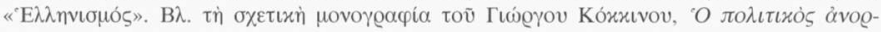

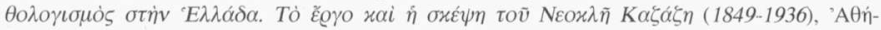

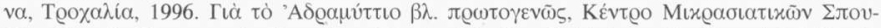

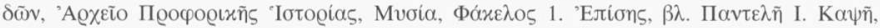

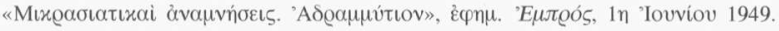

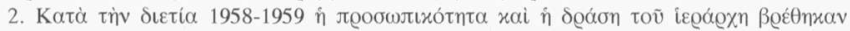

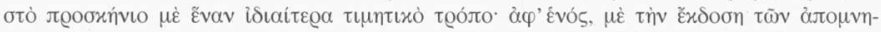


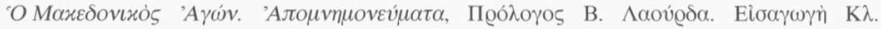

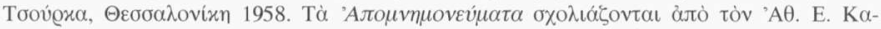

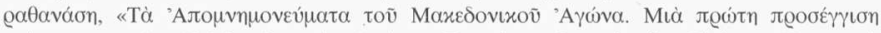

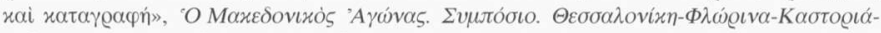

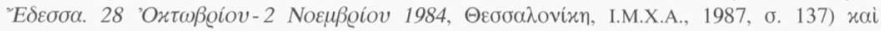

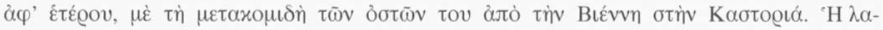

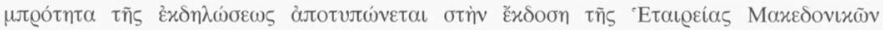

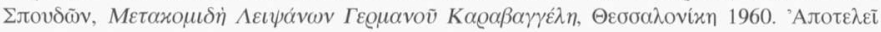

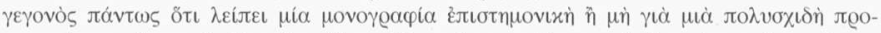

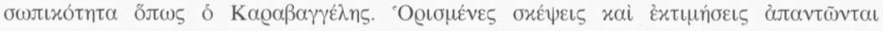

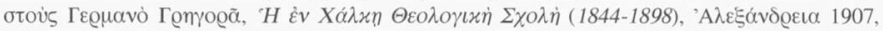

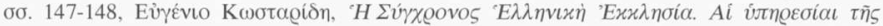

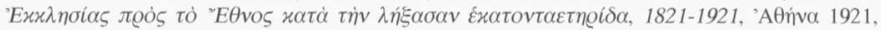

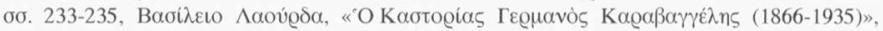

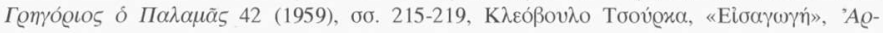

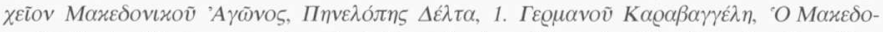
vıxòs 'A

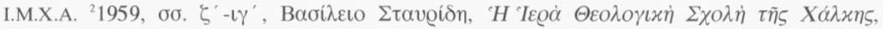

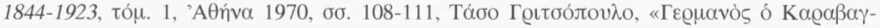




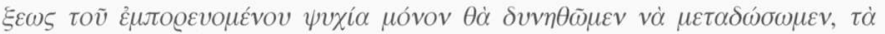

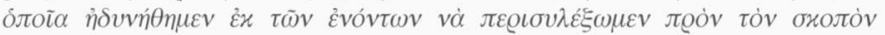

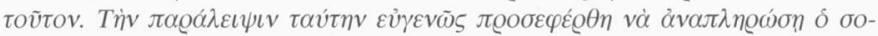

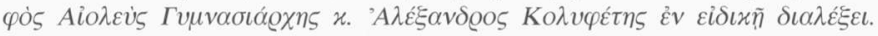

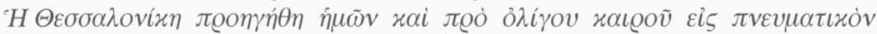

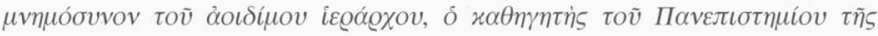

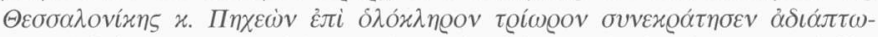

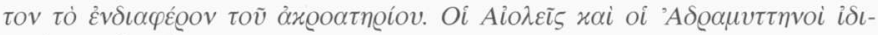

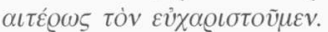

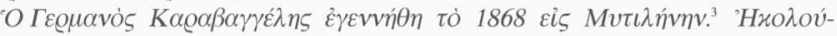

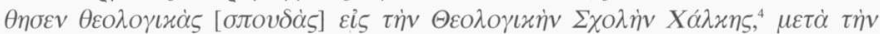

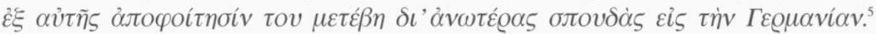

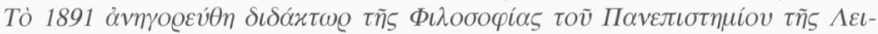

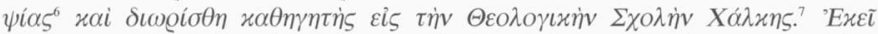

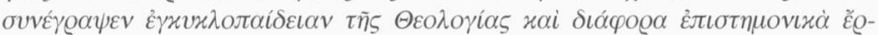

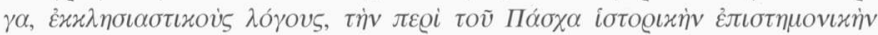

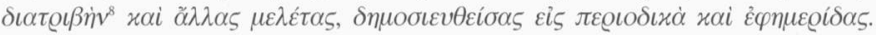

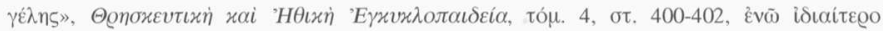

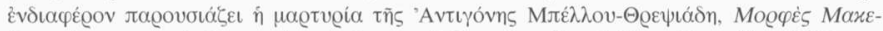

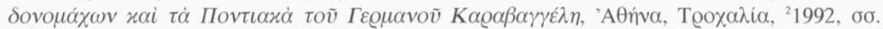

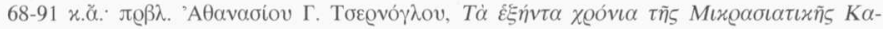

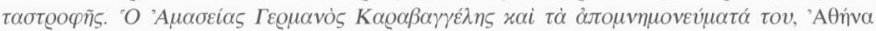

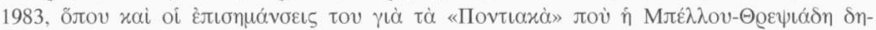

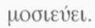

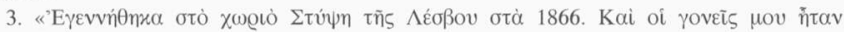

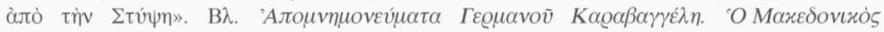

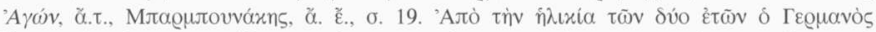

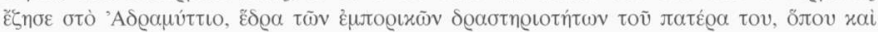

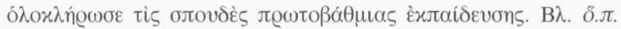

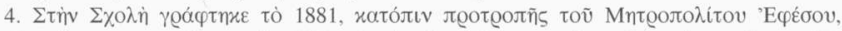
'A $\alpha \alpha \theta \alpha \gamma \gamma \varepsilon \hat{\lambda}$ ov. 'A

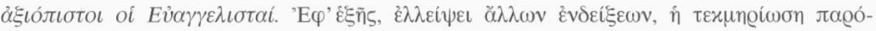

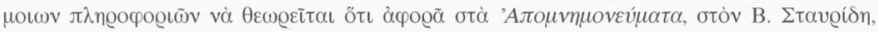

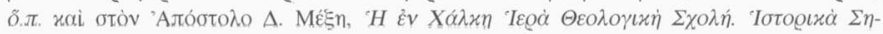

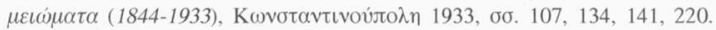

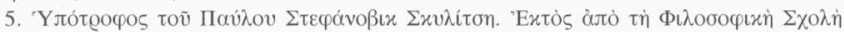

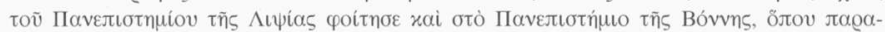

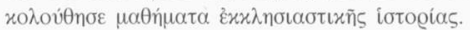

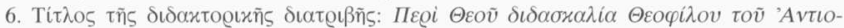

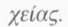

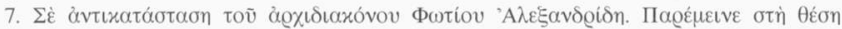

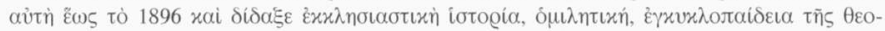

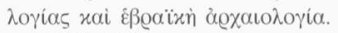

8. Tò 1895. 


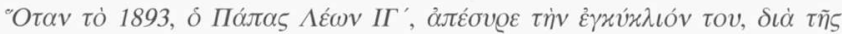

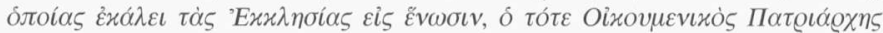

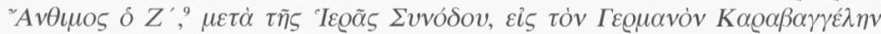

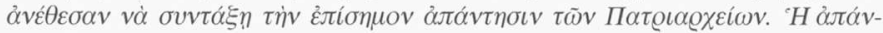

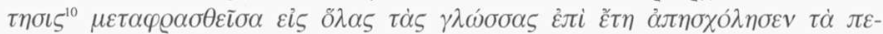

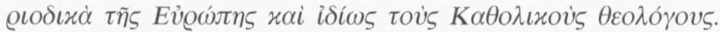

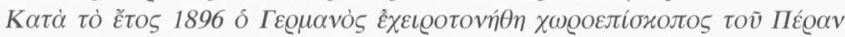

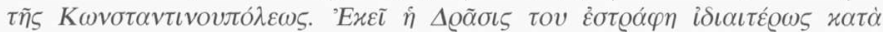

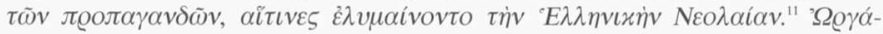

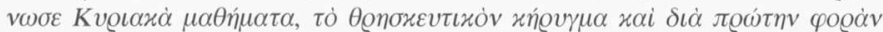

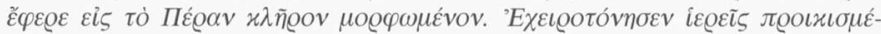

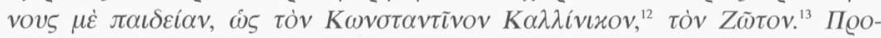

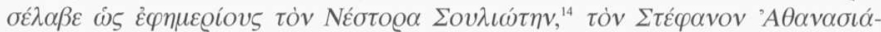

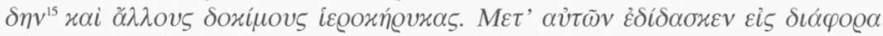

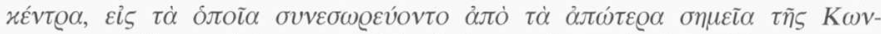

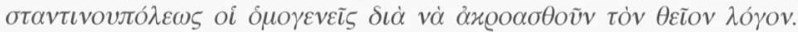

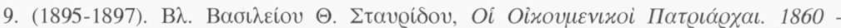

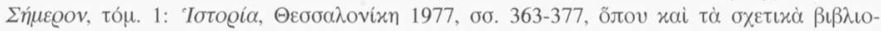

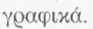

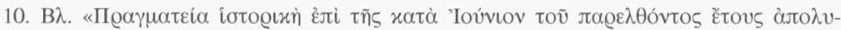

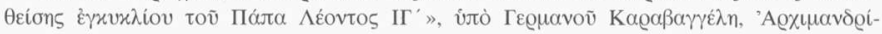

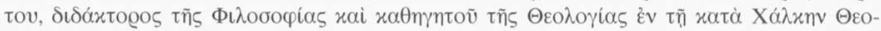

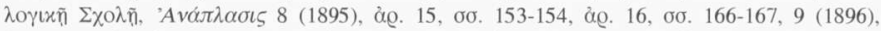

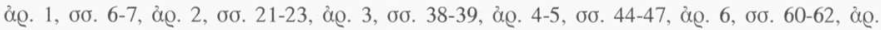

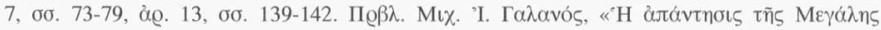

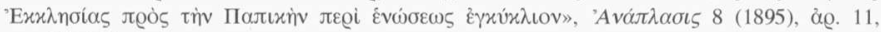
бб. 119-120.

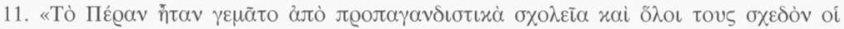

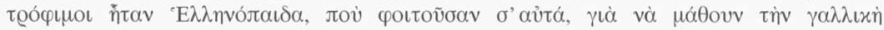

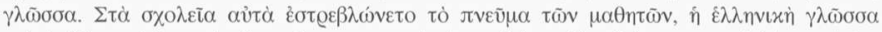

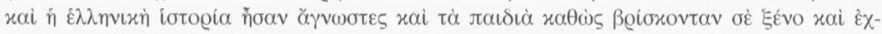

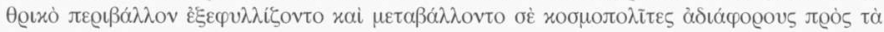

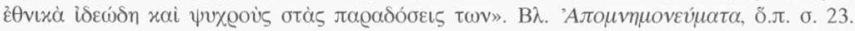

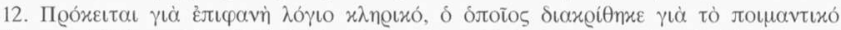

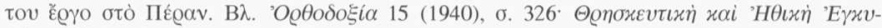

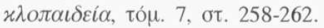

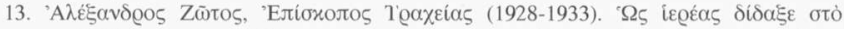

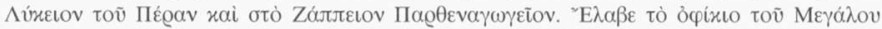

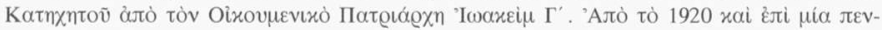

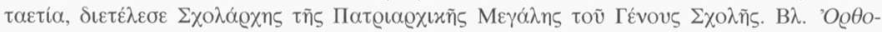

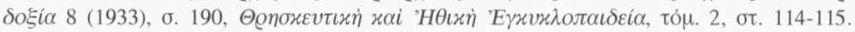

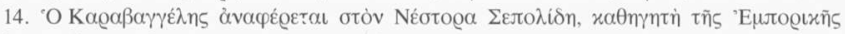

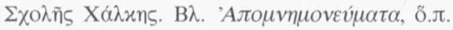

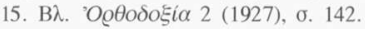




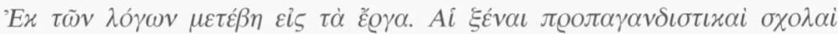

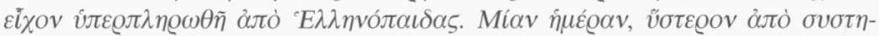

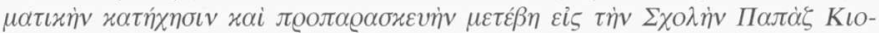

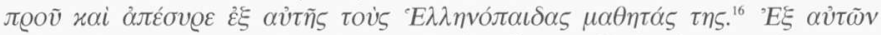

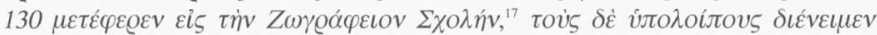

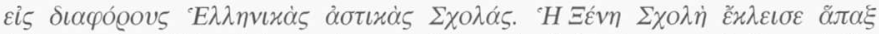

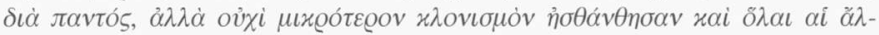

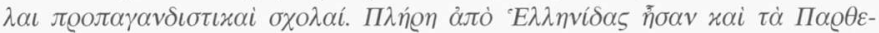

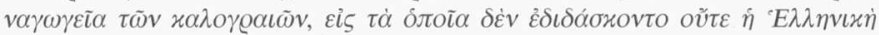

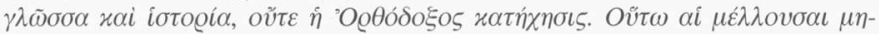

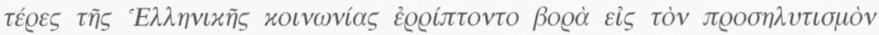

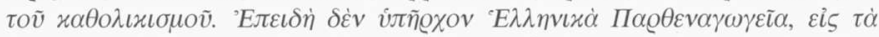

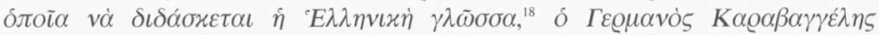

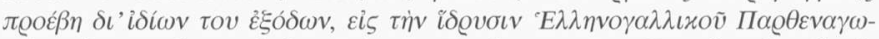

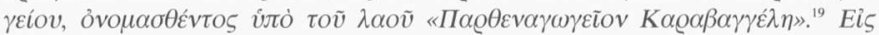

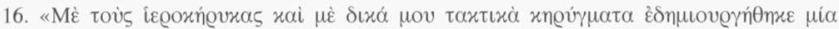

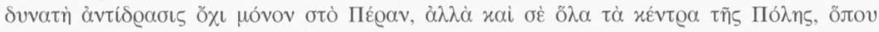

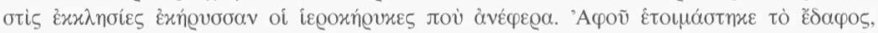

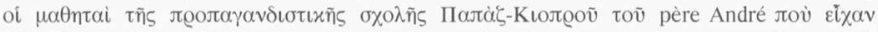

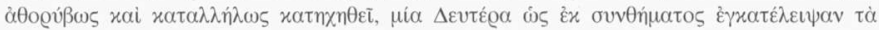

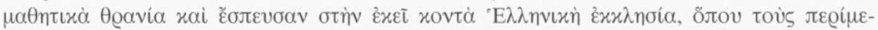

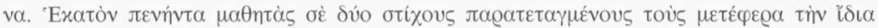

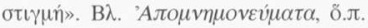

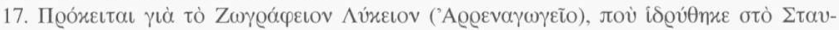

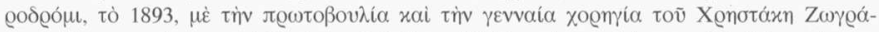

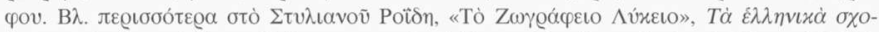

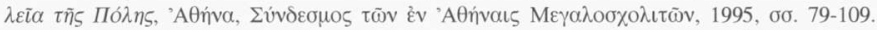

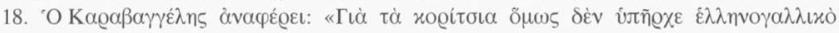

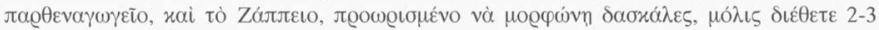

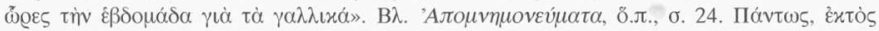

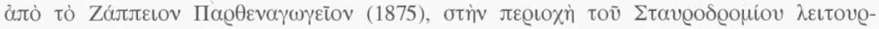

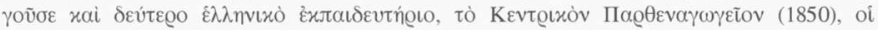

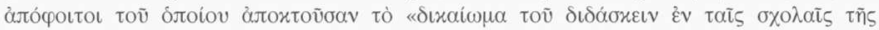

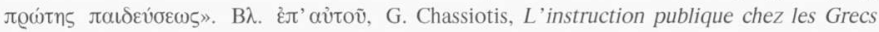
depuis la Prise de Constantinople par les Turcs jusqu' à nos jours, Парiбı 1881, бб. 401-411,

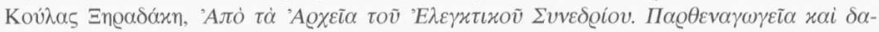

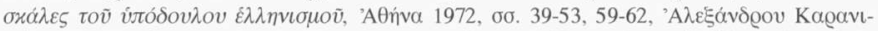

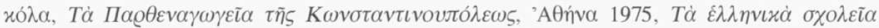

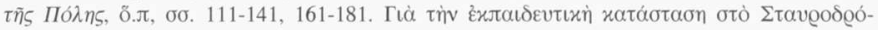

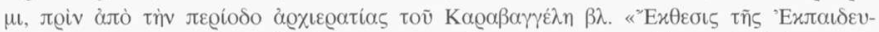

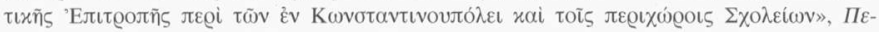

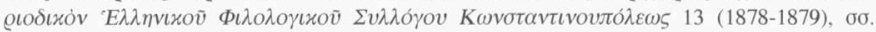
81-82.

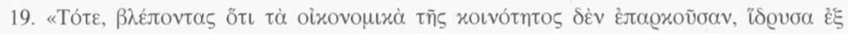




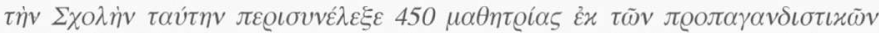

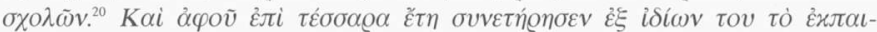

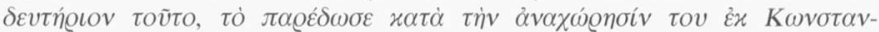

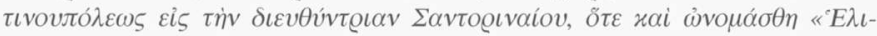
$x\left(\dot{v} v{ }^{21}\right.$

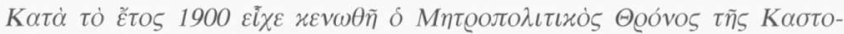

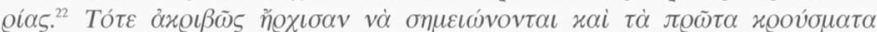

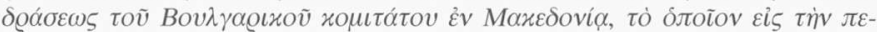

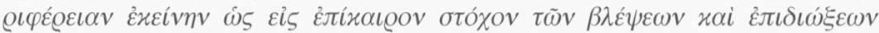

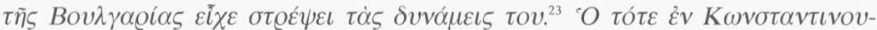

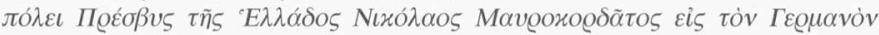

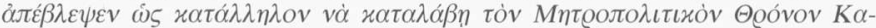

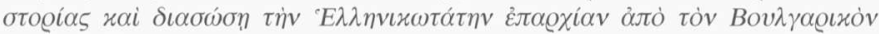

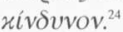

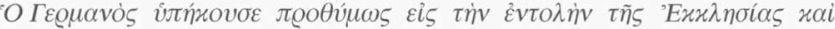

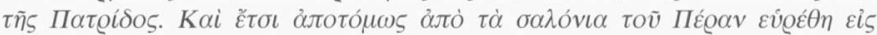

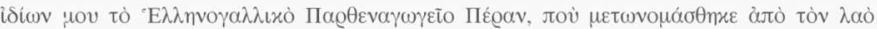

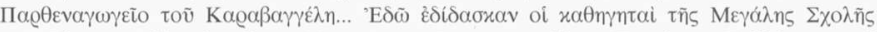

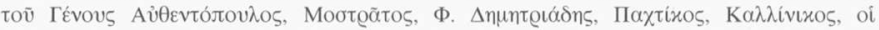

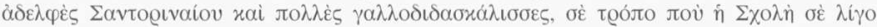

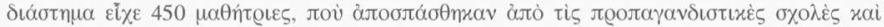

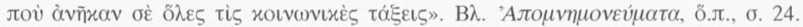

20. $\mathrm{B} \lambda ., \quad \delta . \pi$

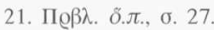

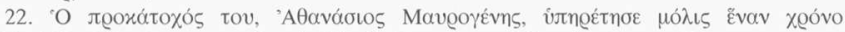

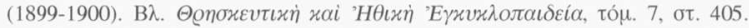

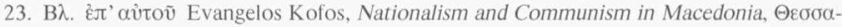

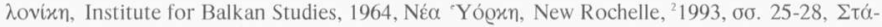

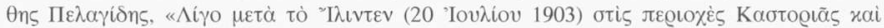

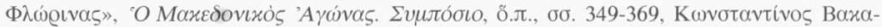

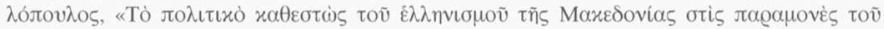

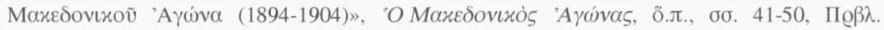

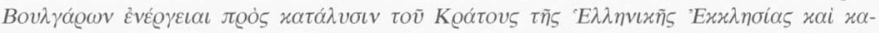

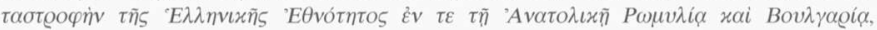

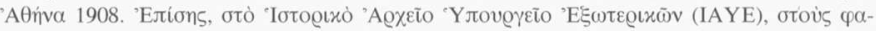

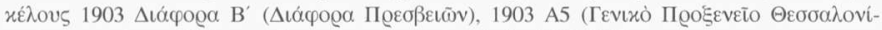

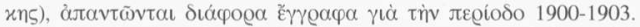

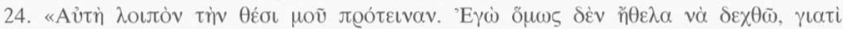

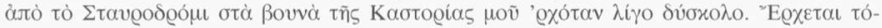

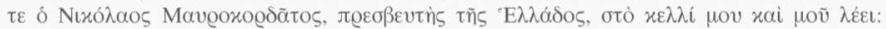

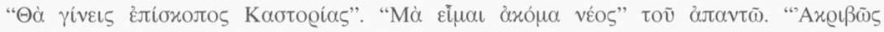

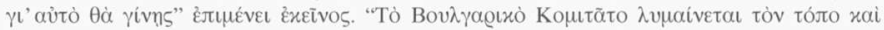

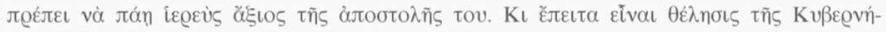

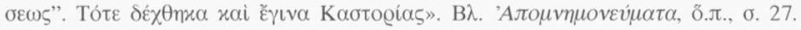




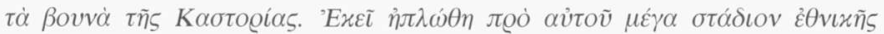

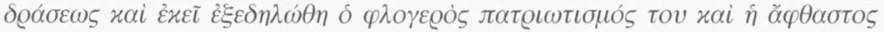

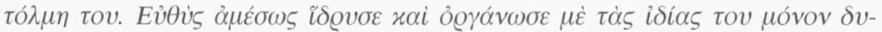

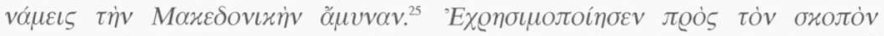

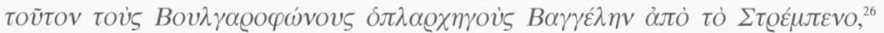

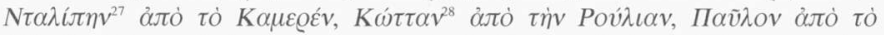

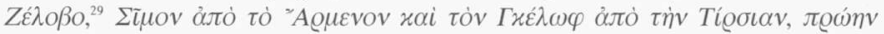

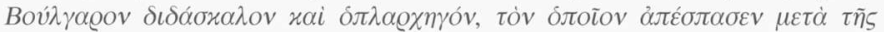

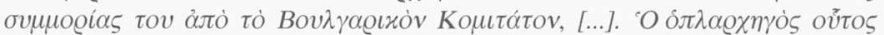

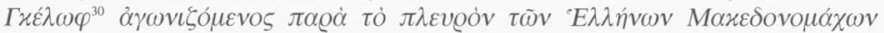

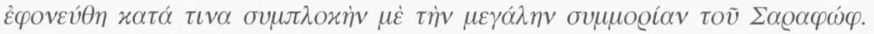

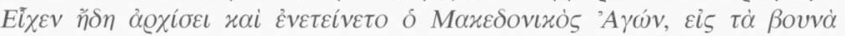

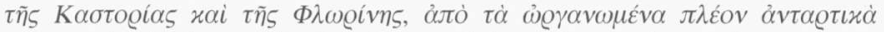

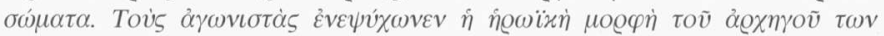

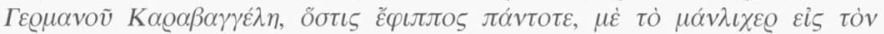

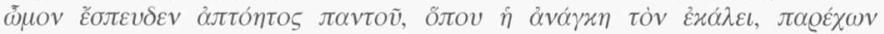

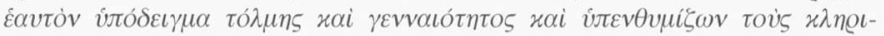

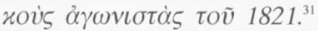

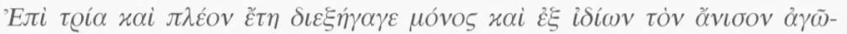

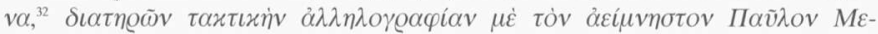

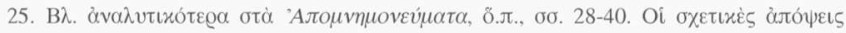

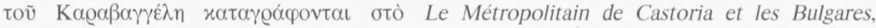

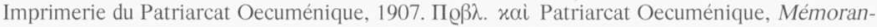
dums adressés aux représentants des grandes puissances à Constantinople et autres documents relatifs aux récents événements de Bulgarie et de Roumélie Orientale, Imprimerie du Patriarcat Oecuménique, 1906.

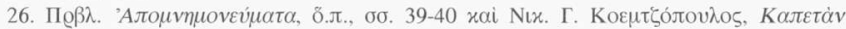

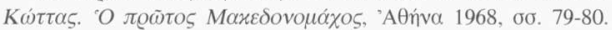

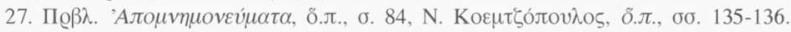

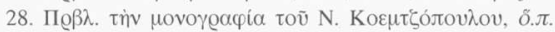

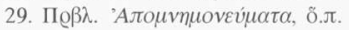

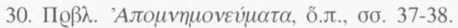

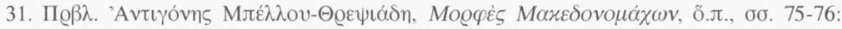

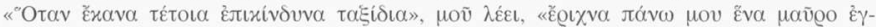

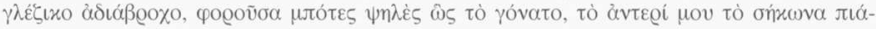

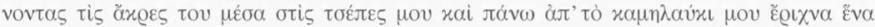

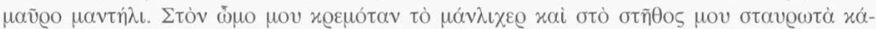

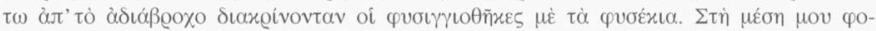

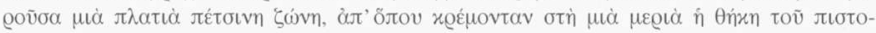

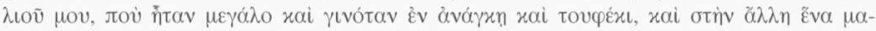

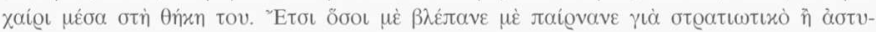
voutxó».

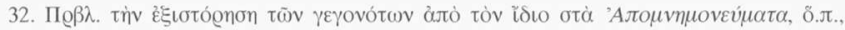
бб. 40-100. 


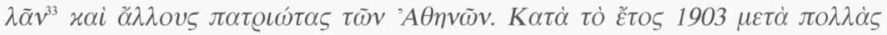

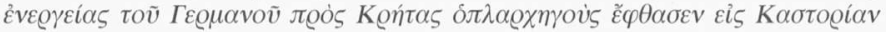

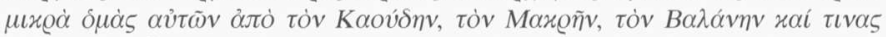

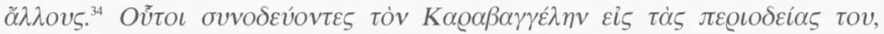

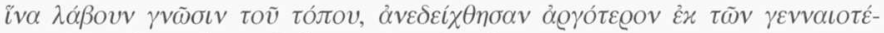

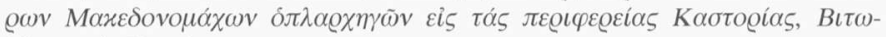
$\lambda i \omega v$ xai $\Phi \lambda \omega \varrho i v \eta s$.

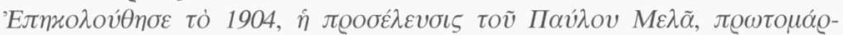

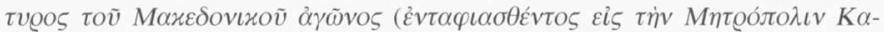

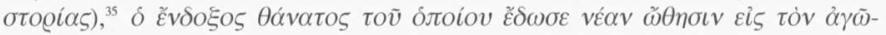

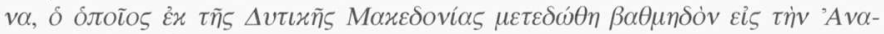

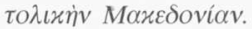

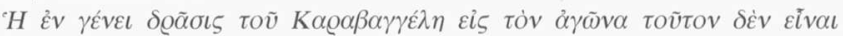

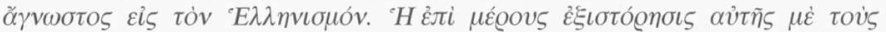

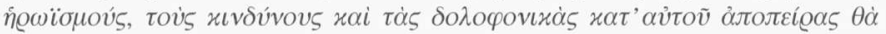

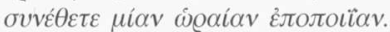

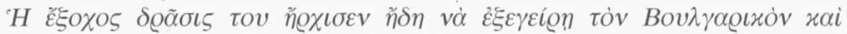

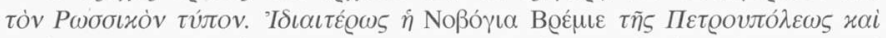

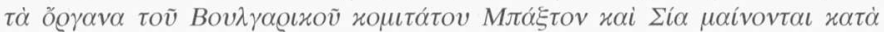

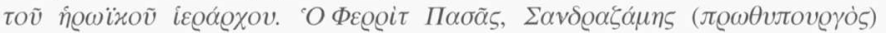

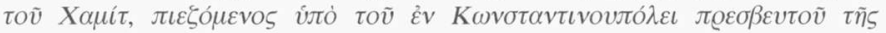

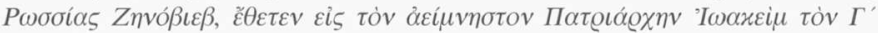

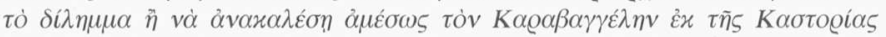

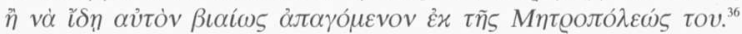

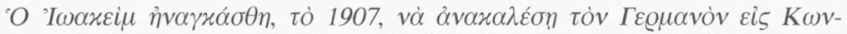

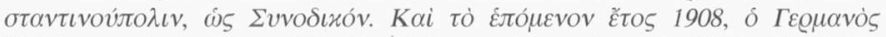

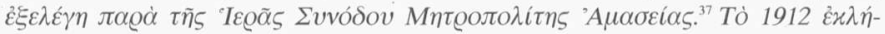

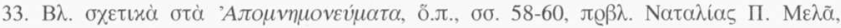

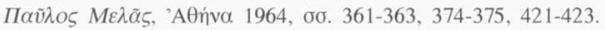

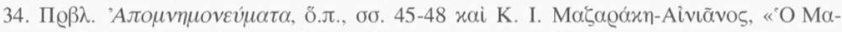

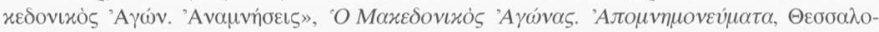
virฑ, I.M.X.A., 1984 , б. 177.

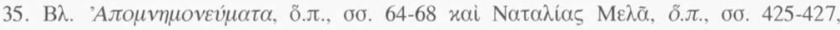

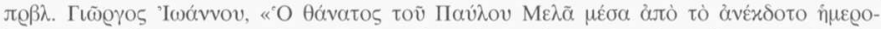

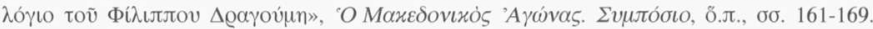

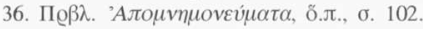

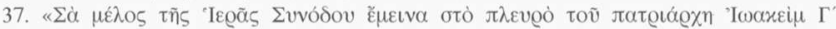

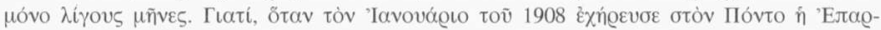

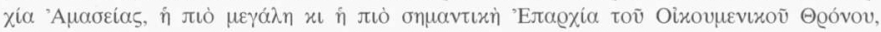

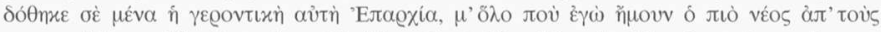

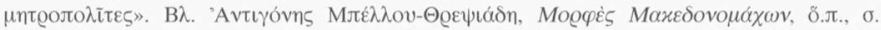

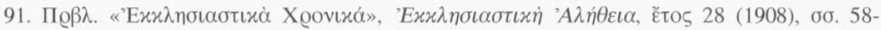

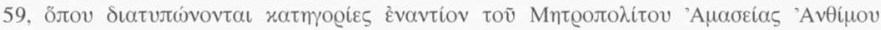




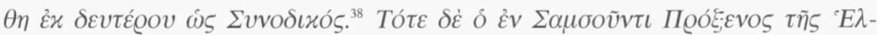

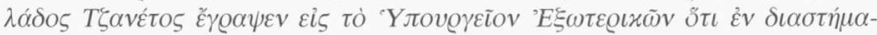

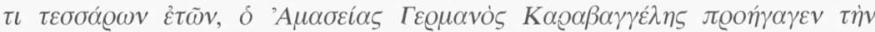

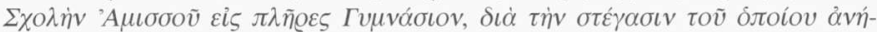

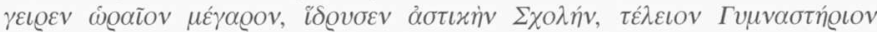

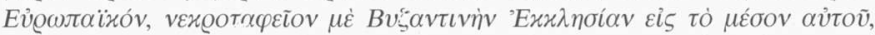

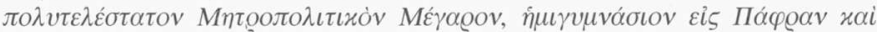

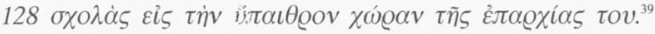

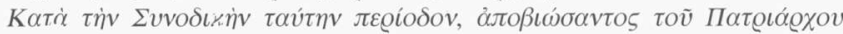

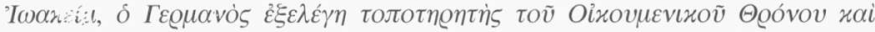

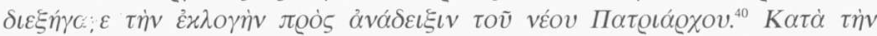

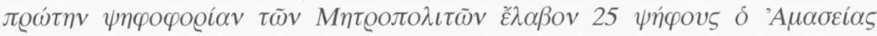

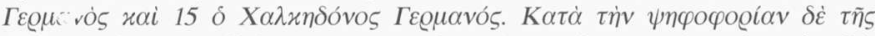

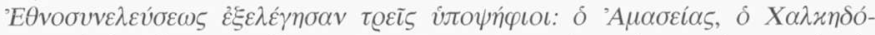

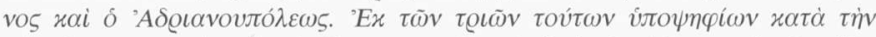

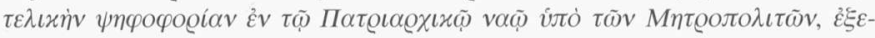

'A

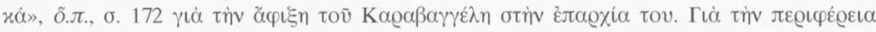

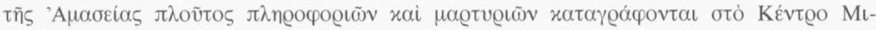

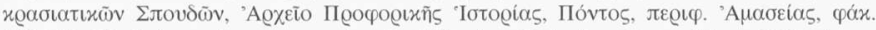

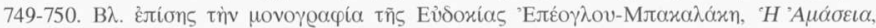

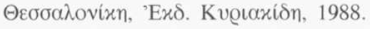

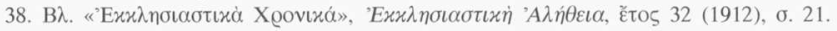

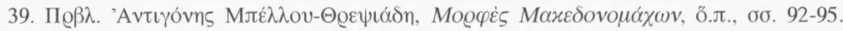

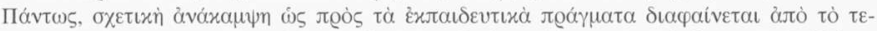

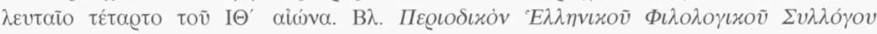

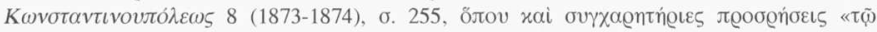

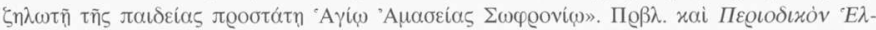

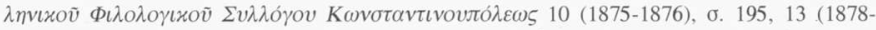

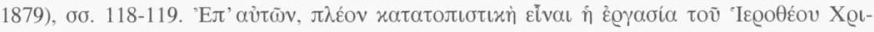

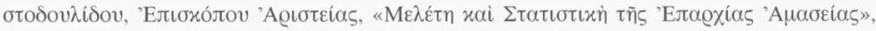

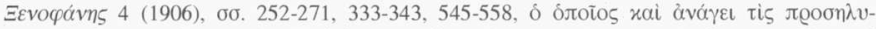

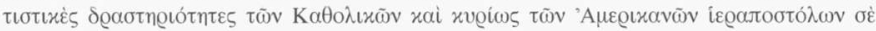

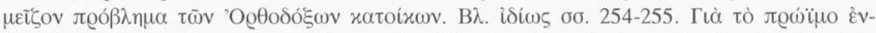

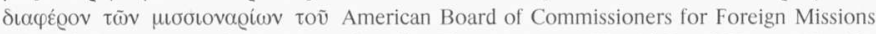

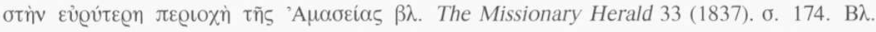

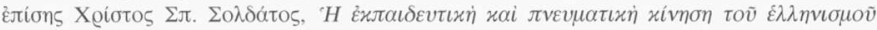

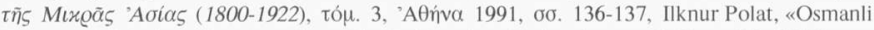
Imparatorluğu'nda açilan Amerikan Okullari üzerine bir inceleme», Belleten 52 (1988), бб. 642-646.

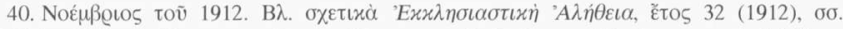

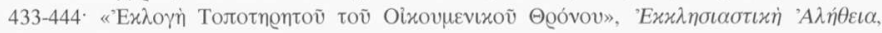
ठ̈.л., б. 451. 


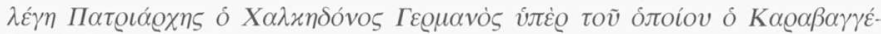

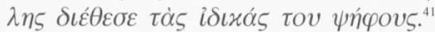

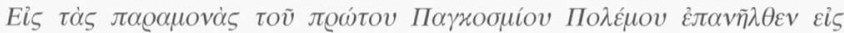

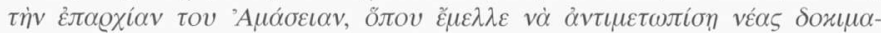

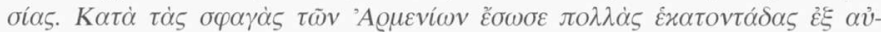

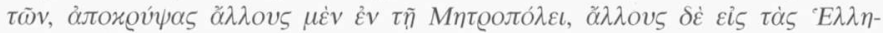

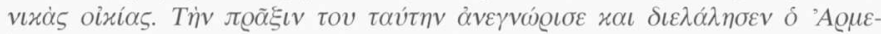

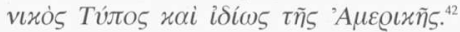

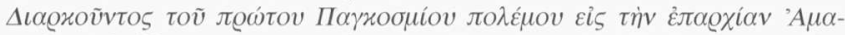

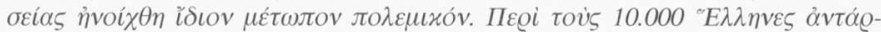

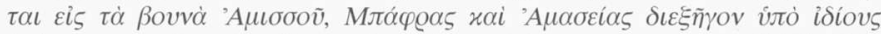

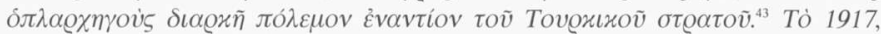

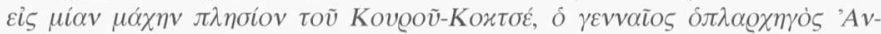

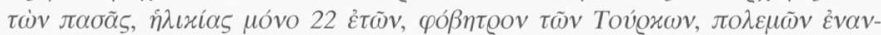

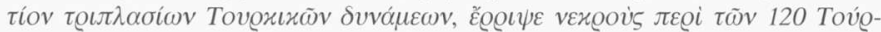

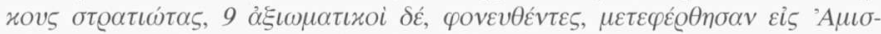

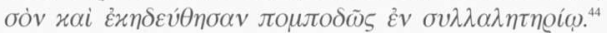

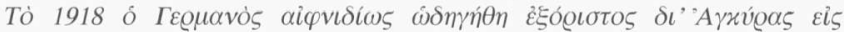

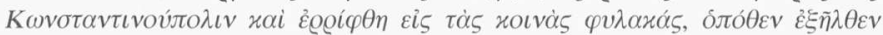

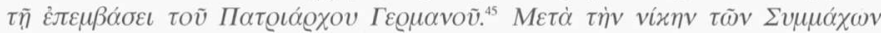

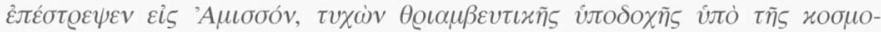

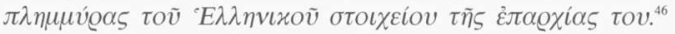

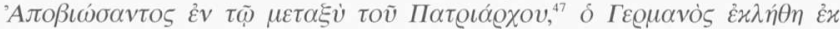

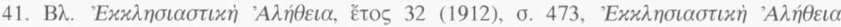

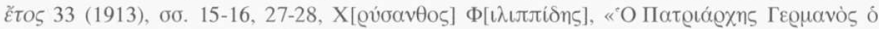

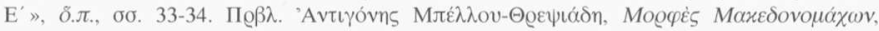
ठ̈.л., б. 96 .

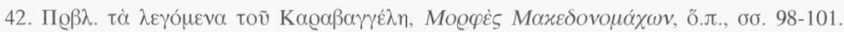

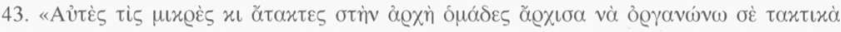

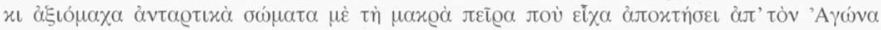

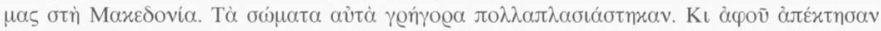

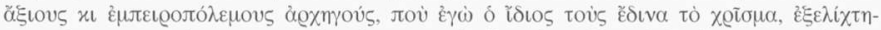

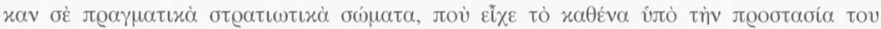

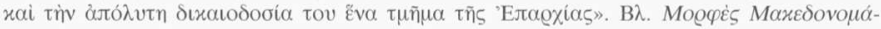

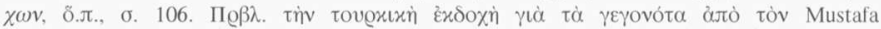
Balcioğlu, «Birinci Dünya Savaşi sirasinda Karadeniz' de Rum faaliyetleri ve sivil tepki», Osmanli Tarihi Araştirma ve Uygulama Merke>i Dergisi (OTAM), å@. 4 (1993), бo. 91-97.

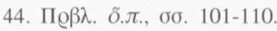

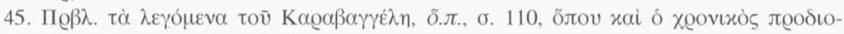

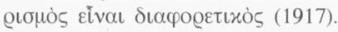

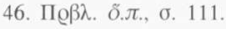

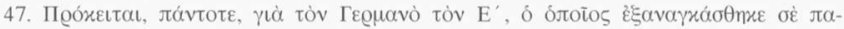

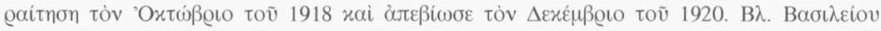




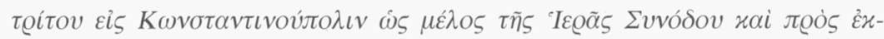

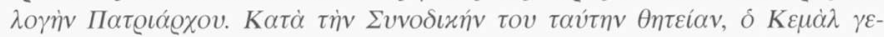

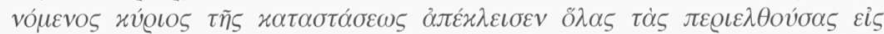

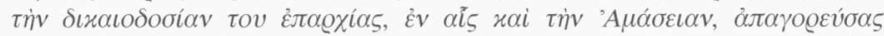

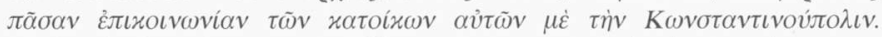

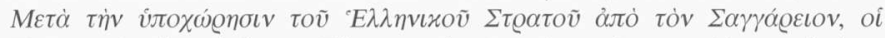

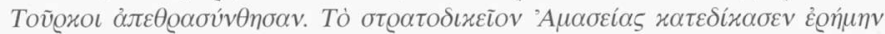

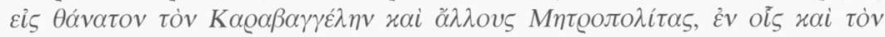

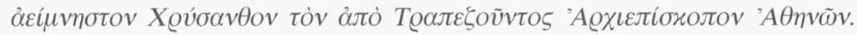

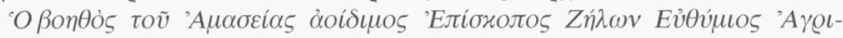

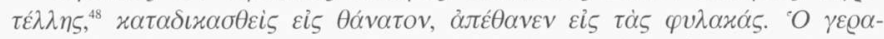

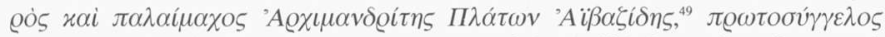

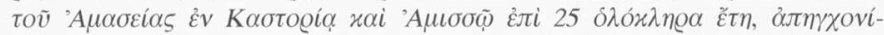

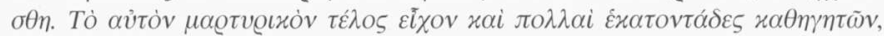

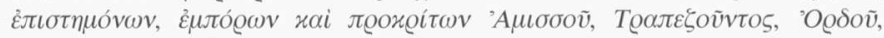

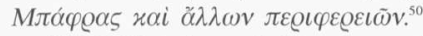

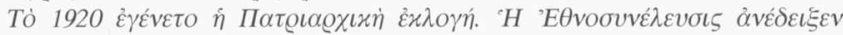

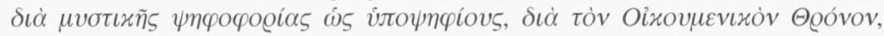

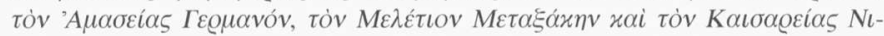

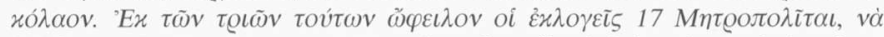

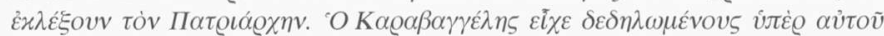

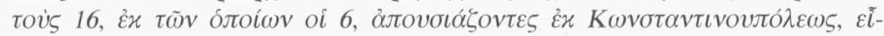

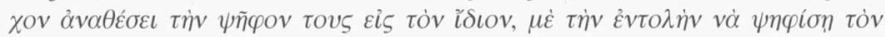

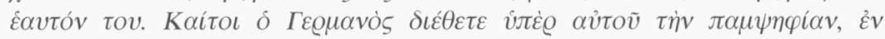

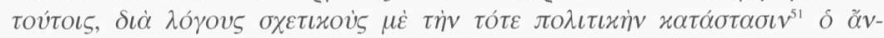

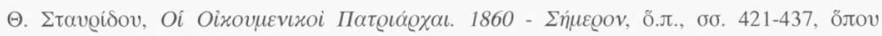

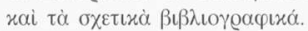

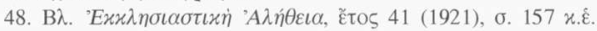

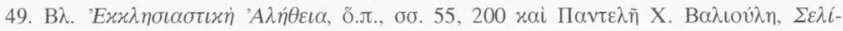

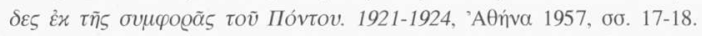

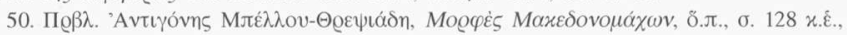
Les atrocités turques au Pont-Euxin, Copie d'une lettre de S.E. I'Archevêque d'Amassia et

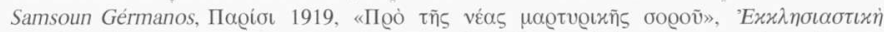

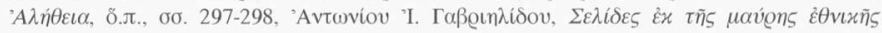

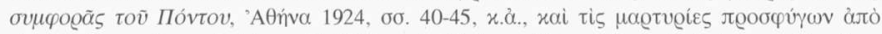

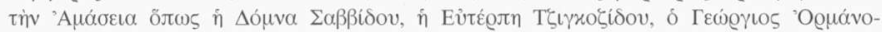

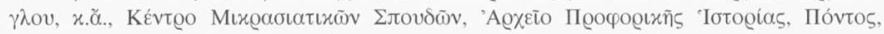

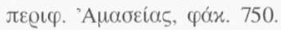

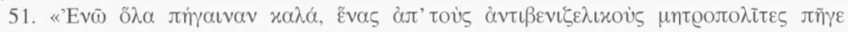

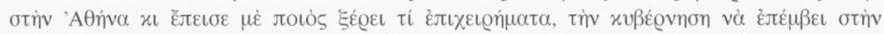

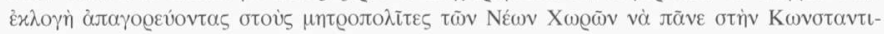

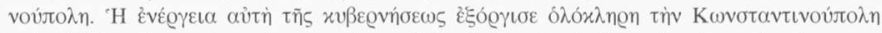

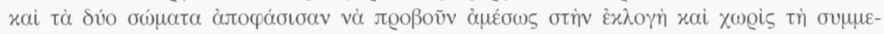




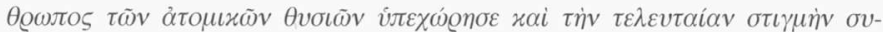

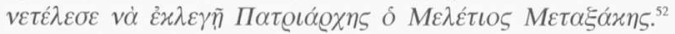

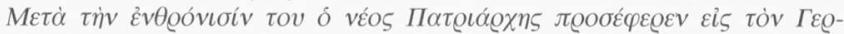

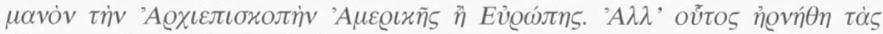

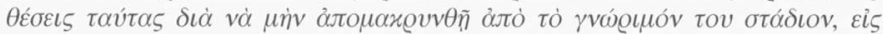

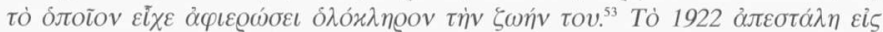

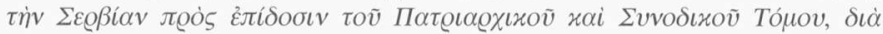

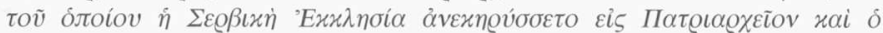

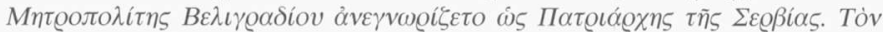

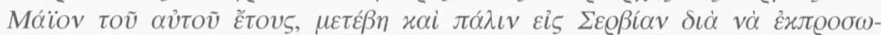

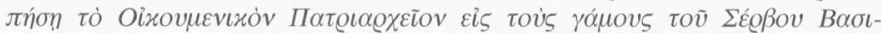

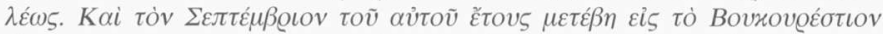

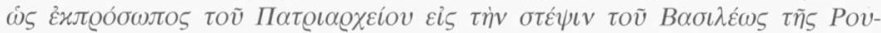

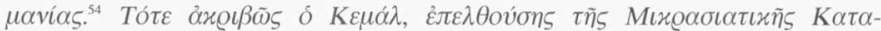

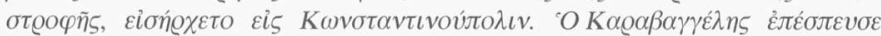

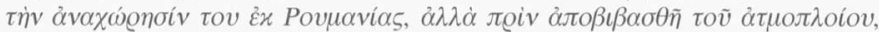

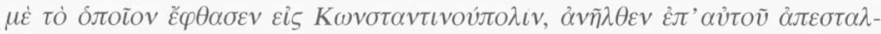

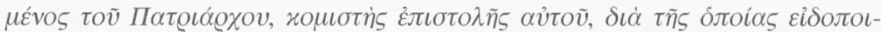

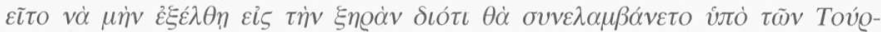

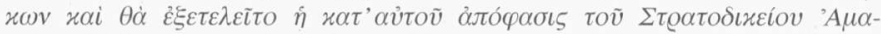

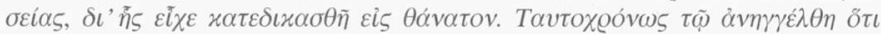

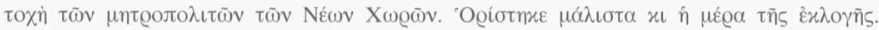

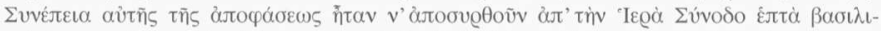

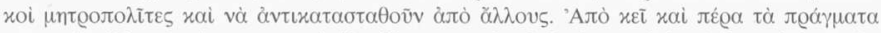

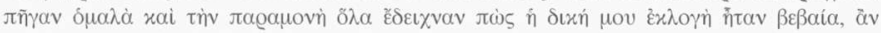

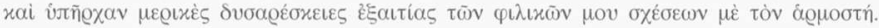

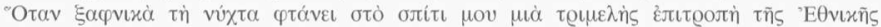

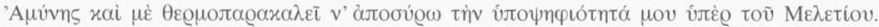

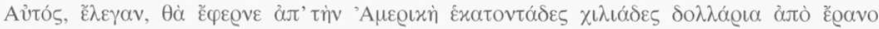

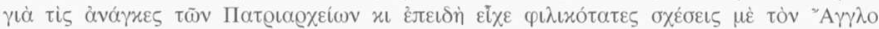

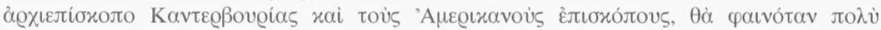

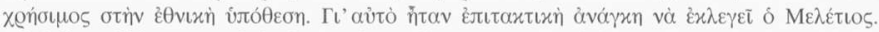

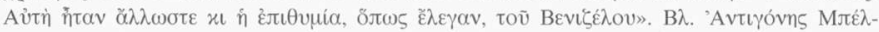

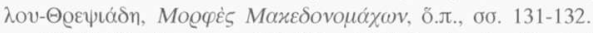

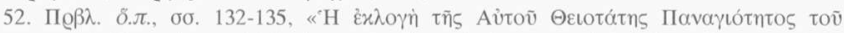

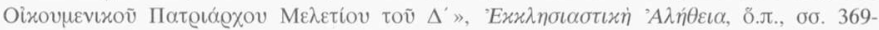

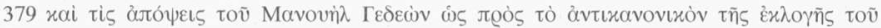

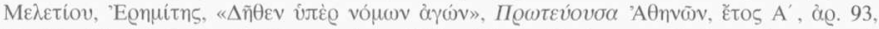

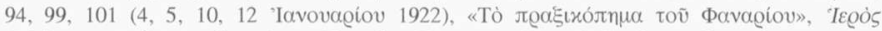

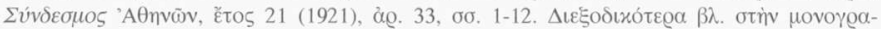

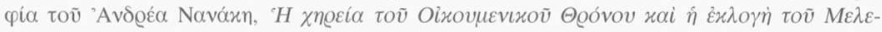

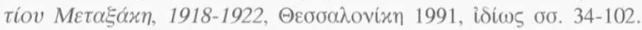

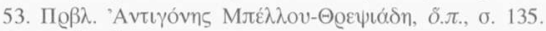

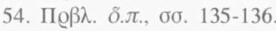




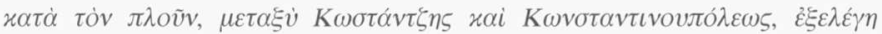

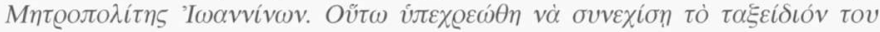

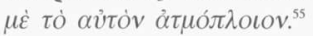

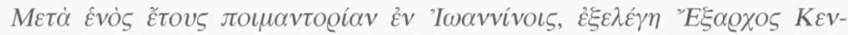

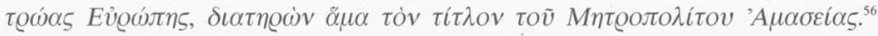

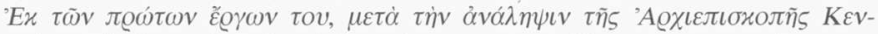

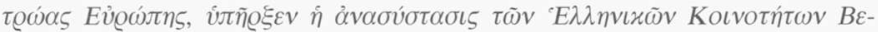

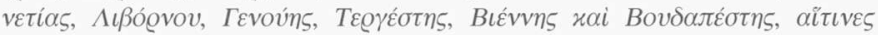

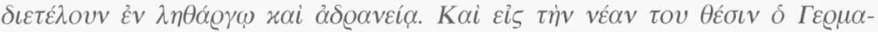

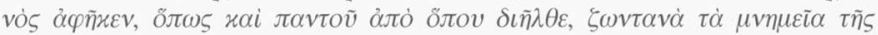

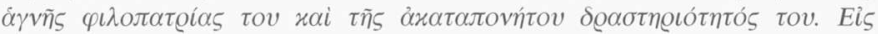

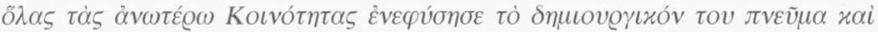

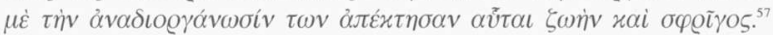

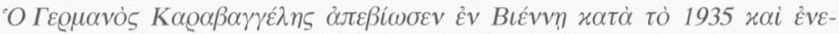

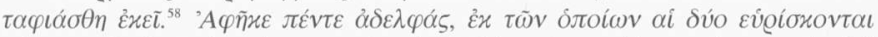

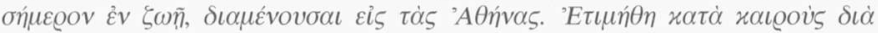

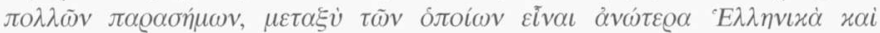

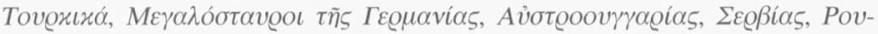

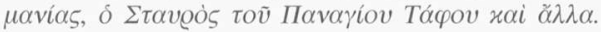

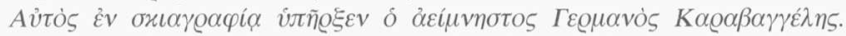

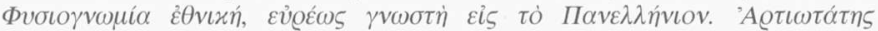

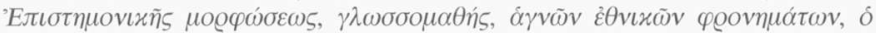

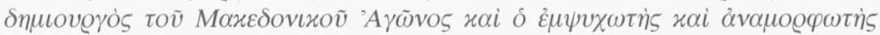

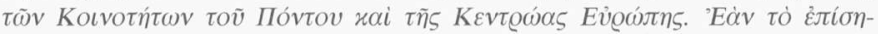

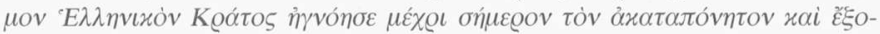

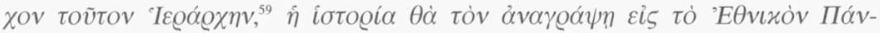

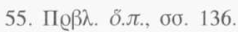

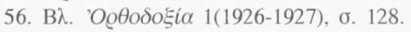

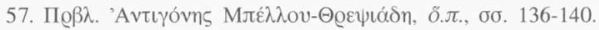

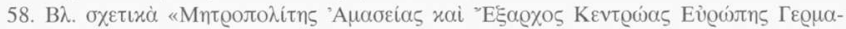

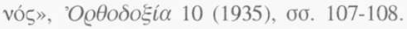

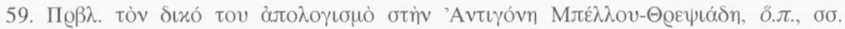

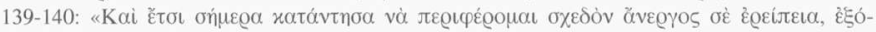

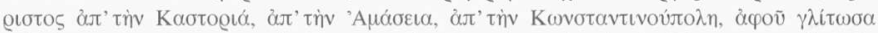

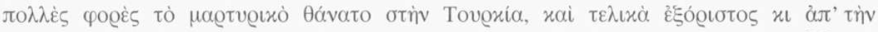

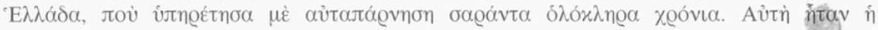

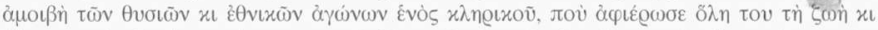

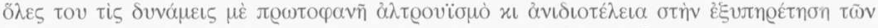

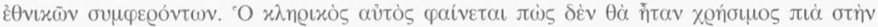

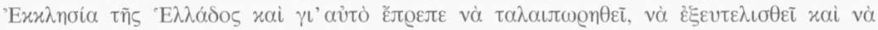

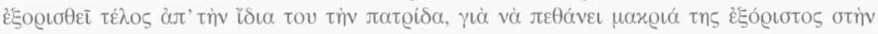

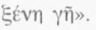




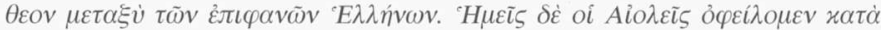

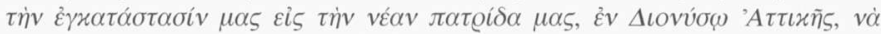

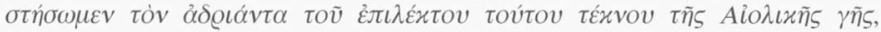

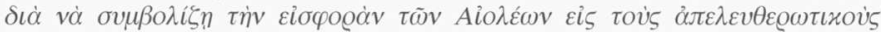

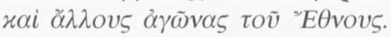




\section{ПАРАРТНМА}

\section{IEPA MHTPOПO $\Lambda$ I $\Sigma$ AMA $\Sigma E I A \Sigma$}

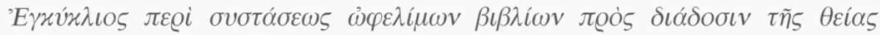

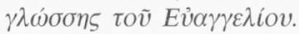

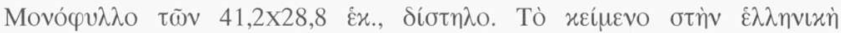

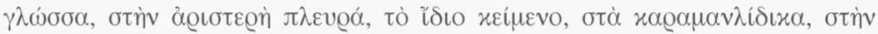
$\delta \varepsilon \xi \iota \dot{\alpha} \pi \lambda \varepsilon v \varrho \alpha ́$.

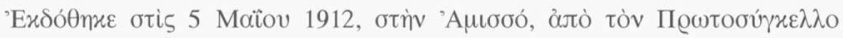

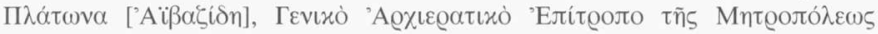

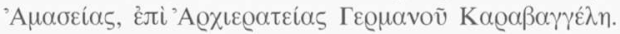

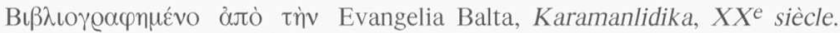
Bibliographie analytique, 'A $\theta \dot{n} v \alpha$, Centre d'Etudes d'Asie Mineure, 1987, б. 100 (à.x. 80).

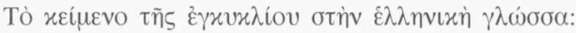

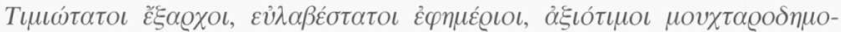

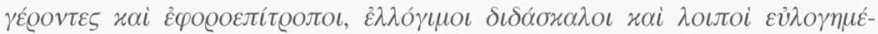

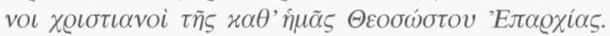

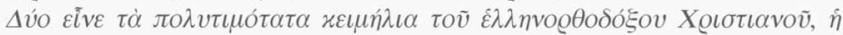

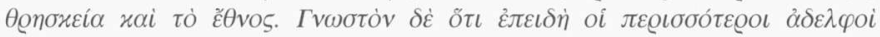

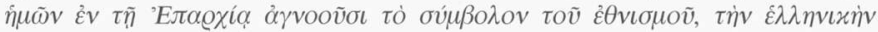

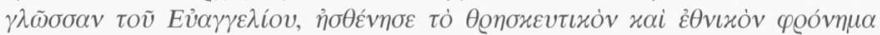
$\tau \tilde{\omega} v \hat{\sigma} \mu o \delta \sigma ́ \xi \omega v$.

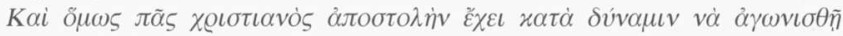

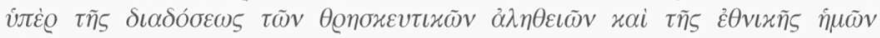
$\gamma \lambda \omega \sigma \sigma \eta \zeta$.

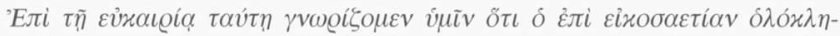

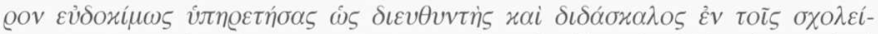

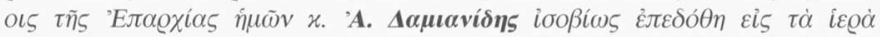

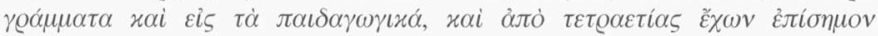

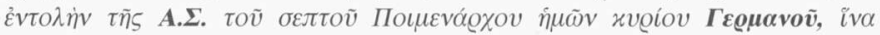

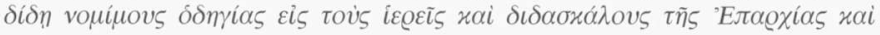




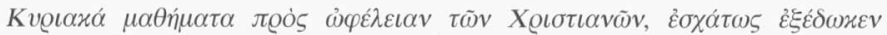

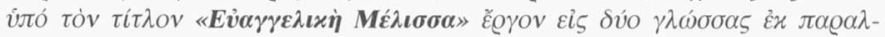
$\lambda \dot{n} \lambda$ ov.

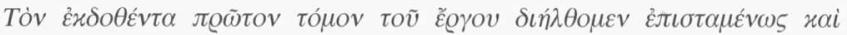

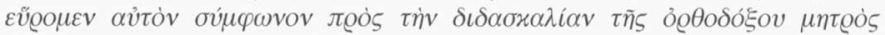

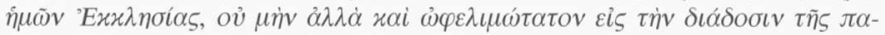

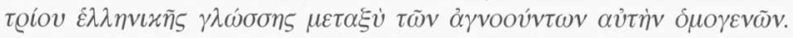

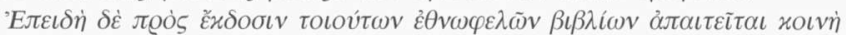

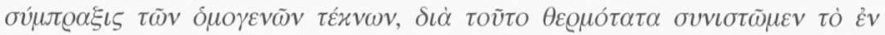

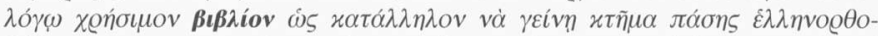

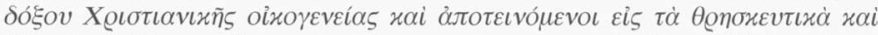

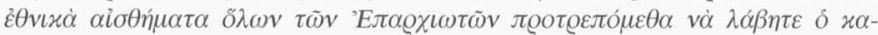

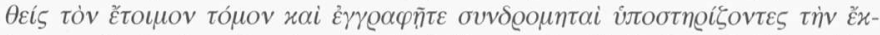

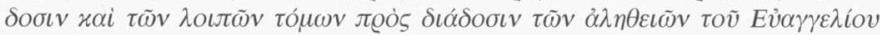

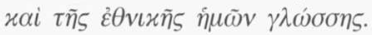

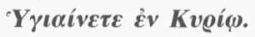

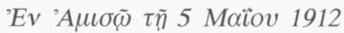

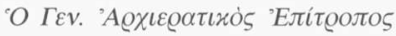

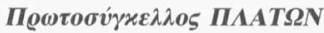




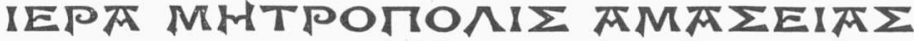

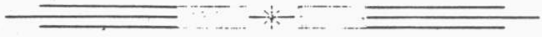

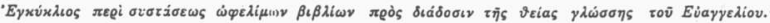

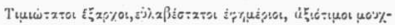

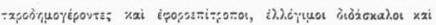

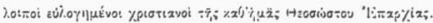

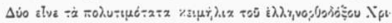

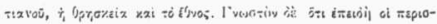

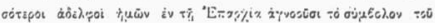

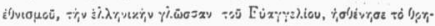

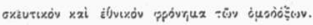

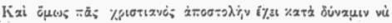

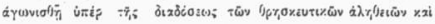

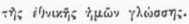

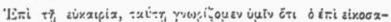

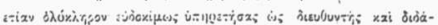

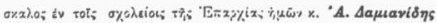
iooßi

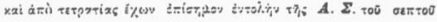

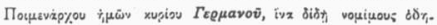

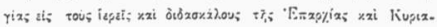

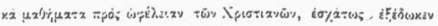

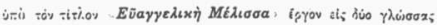
ix $\pi x_{z} z \lambda \lambda \dot{r}_{1} \lambda$.ou.

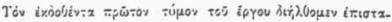

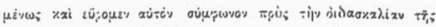

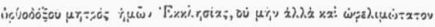

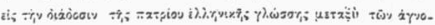

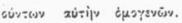

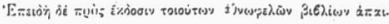

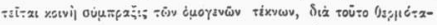

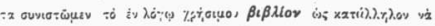

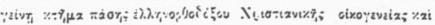

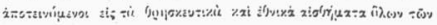

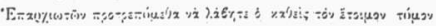

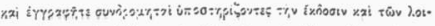

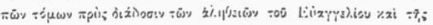

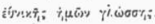

- Y piaivere ì Kvpị.

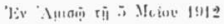

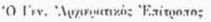

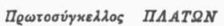

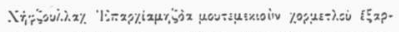

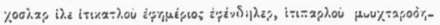

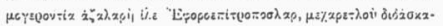

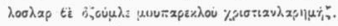

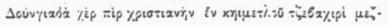

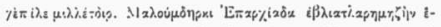

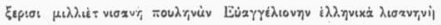

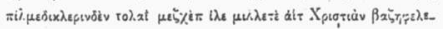

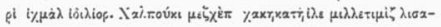

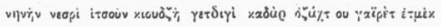

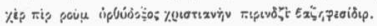

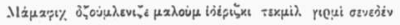

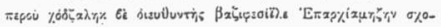

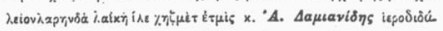

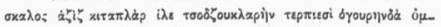

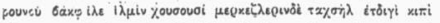

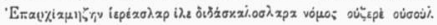

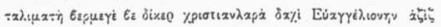

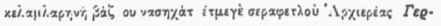

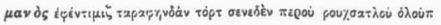

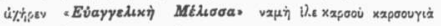

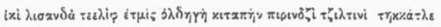

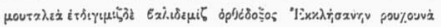

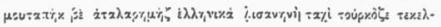

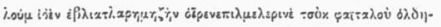

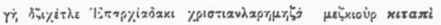

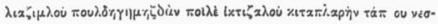

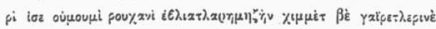

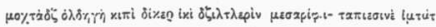

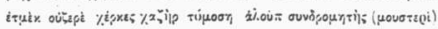

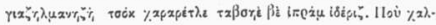

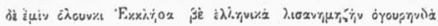

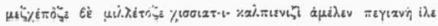

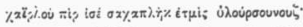

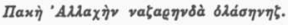

Sunoù 5 Matov 1912

TY A. A. X. APXITEKTONISOY AMais 